\title{
Syndioselective Coordination (Co)Polymerization of Alkyne-Substituted Styrenes Using Rare-earth Metal Catalysts
}

Zhen Zhang, Yanli Dou, Zhongyi Cai, Dongtao Liu, Shihui Li* and Dongmei Cui*

* E-mail: shihui-li@ciac.ac.cn

* E-mail: $\underline{\text { dmcui@ciac.ac.cn }}$

\section{Content}

\section{Experimental Section}

Figure S1-S2. ${ }^{1} \mathrm{H}$ NMR and ${ }^{13} \mathrm{C}$ NMR spectrum of poly(HES).

Figure S3-S5. ${ }^{1} \mathrm{H}$ NMR and ${ }^{13} \mathrm{C}$ NMR spectrum of poly(PES).

Figure S6-S9. ${ }^{1} \mathrm{H}$ NMR, ${ }^{13} \mathrm{C}$ NMR and DEPT ${ }^{135}$ spectrum of poly(TES).

Figure S10. ${ }^{1} \mathrm{H}$ NMR spectrum of copolymers with different TES contents.

Figure S11. Plots of the contents of poly(TES) and polystyrene units in the copolymers versus the conversions.

Figure S12-S13. ${ }^{1} \mathrm{H}$ NMR and ${ }^{13} \mathrm{C}$ NMR spectrum of poly(ESt).

Figure S14. ${ }^{1} \mathrm{H}$ NMR spectrum of 1-azido-2-methoxybenzene functionalized poly(ESt).

Figure S15. ${ }^{13} \mathrm{C}$ NMR spectrum of $\mathrm{CO}_{2}$ functionalized poly(ESt).

Figure S16. ${ }^{13} \mathrm{C}$ NMR spectrum of anthraldehyde functionalized poly(ES).

Figure S17. FTIR stack plots of poly(ESt) and anthraldehyde functionalized poly(ESt).

Figure S18A-S18B. The anthraldehyde functionalized poly(ESt) in sunlight and UVlight $(365 \mathrm{~nm})$.

Figure S19-S39. The DSC curve of polymers.

Figure S40-S54. The GPC curve of polymers.

Figure S55. WAXS profiles of alkyne-substituted polystyrenes. 


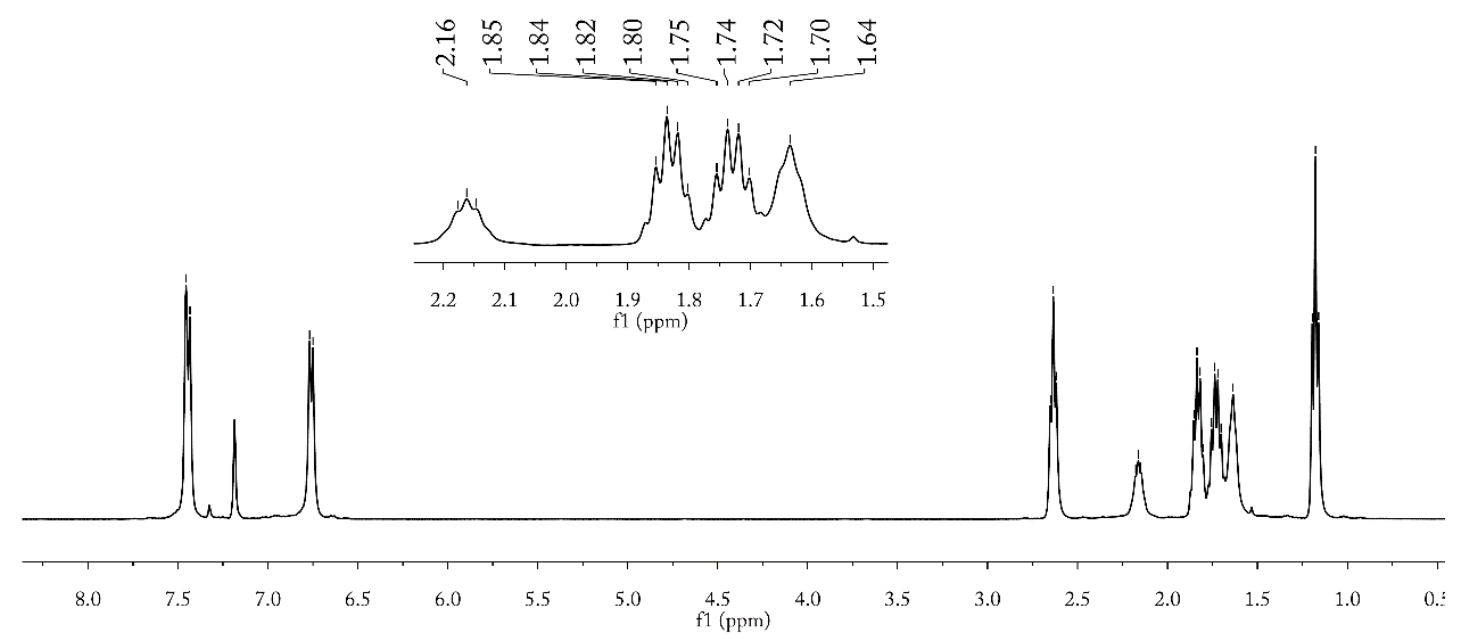

Figure S1. ${ }^{1} \mathrm{H}$ NMR spectrum of poly(HES) $\left(400 \mathrm{MHz}, \mathrm{C}_{6} \mathrm{D}_{2} \mathrm{Cl}_{2}, 110{ }^{\circ} \mathrm{C}\right)$ (Table 1 , run 4).

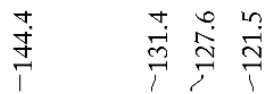

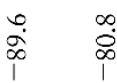

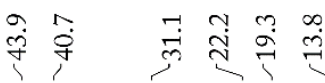

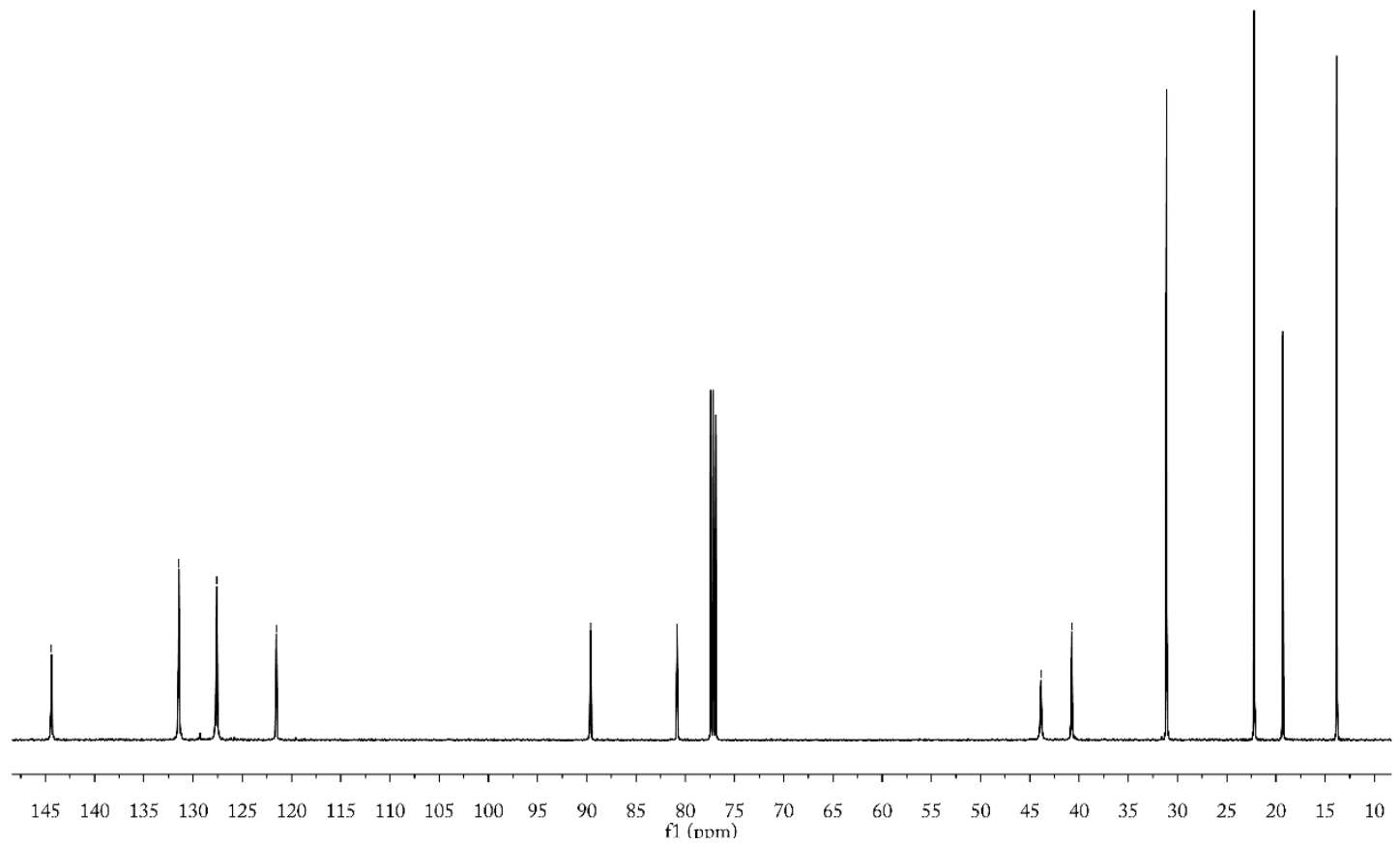

Figure S2. ${ }^{13} \mathrm{C}$ NMR spectrum of poly(HES) $\left(100 \mathrm{MHz}, \mathrm{CDCl}_{3}, 25{ }^{\circ} \mathrm{C}\right)(\mathrm{Table} 1$, run 4). 


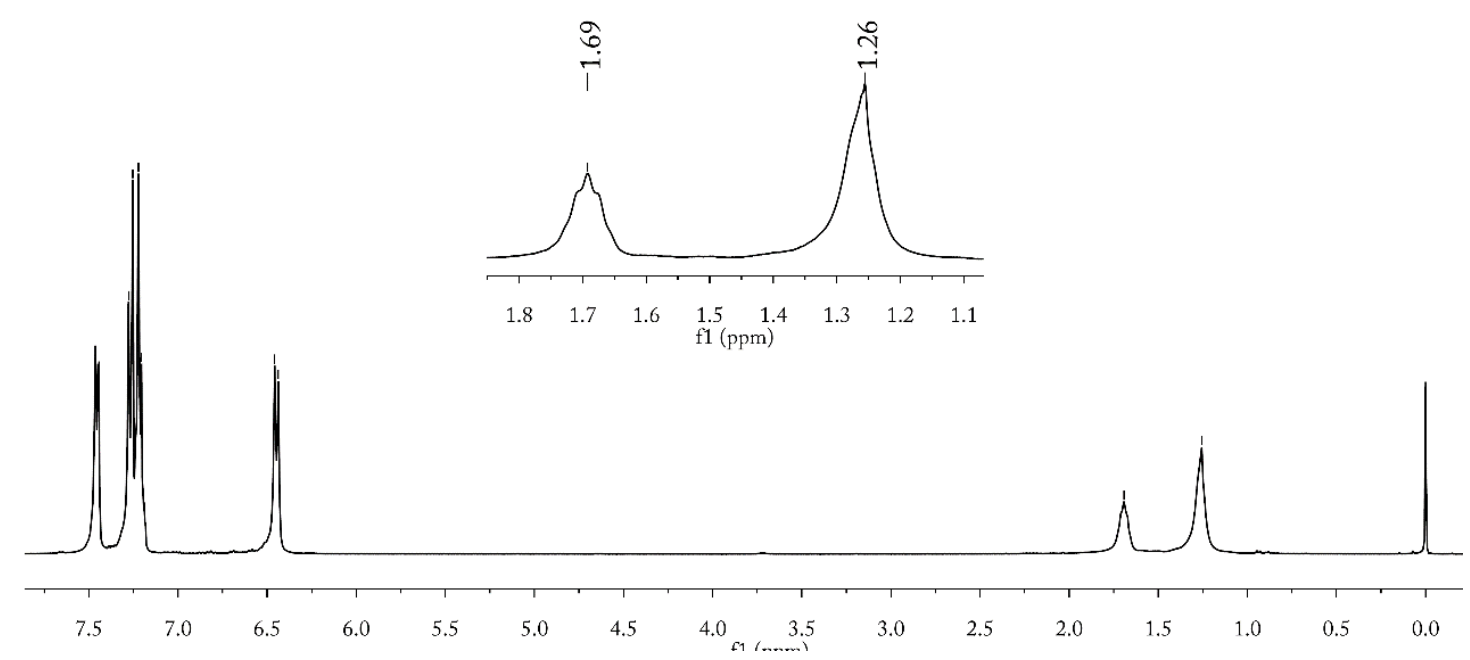

Figure S3. ${ }^{1} \mathrm{H}$ NMR spectrum of poly(PES) $\left(400 \mathrm{MHz}, \mathrm{CDCl}_{3}, 25^{\circ} \mathrm{C}\right)$ (Table 1, run 9).
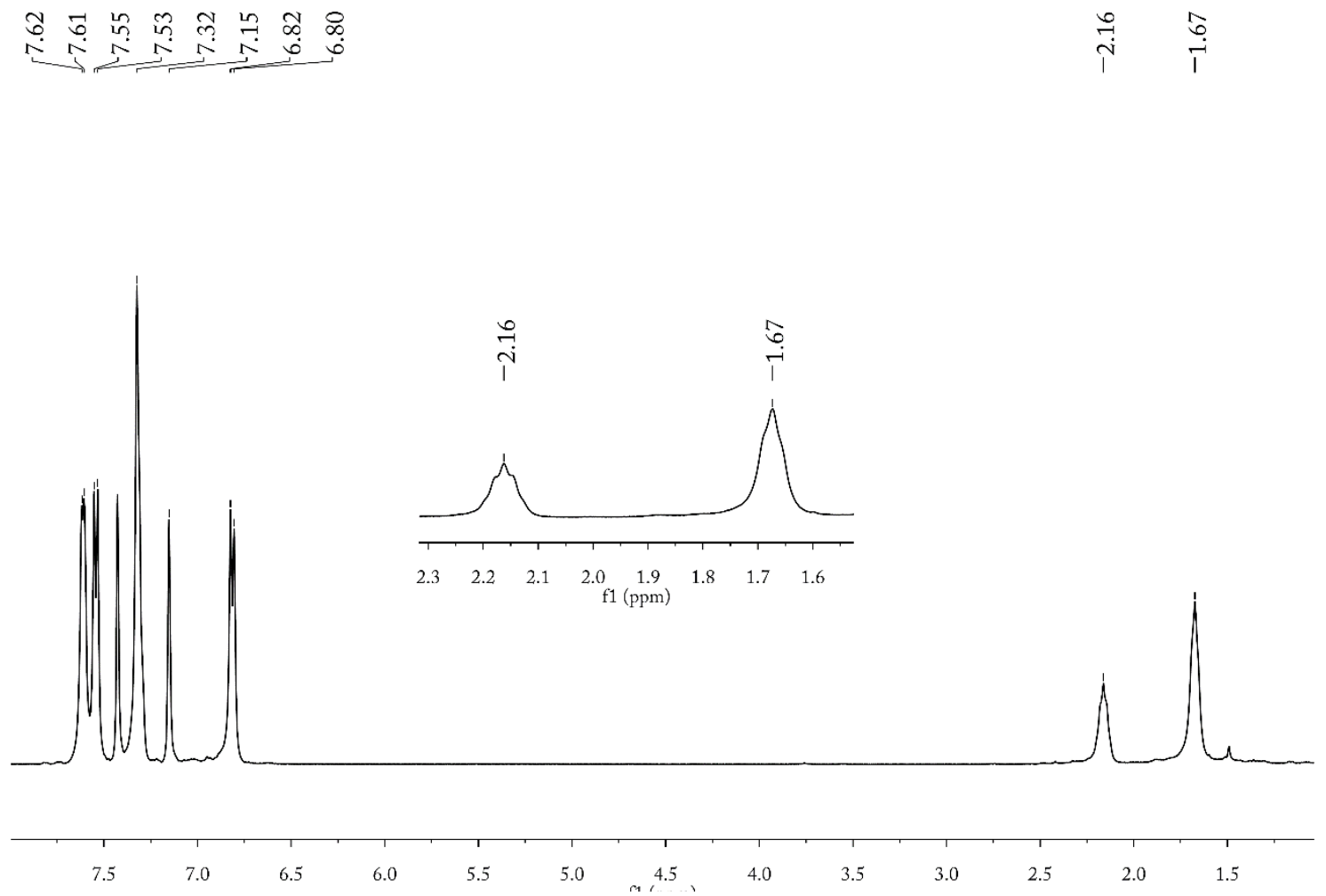

Figure S4. ${ }^{1} \mathrm{H}$ NMR spectrum of poly(PES) $\left(400 \mathrm{MHz}, \mathrm{C}_{6} \mathrm{D}_{2} \mathrm{Cl}_{2}, 110{ }^{\circ} \mathrm{C}\right)($ Table 1 , run 9). 


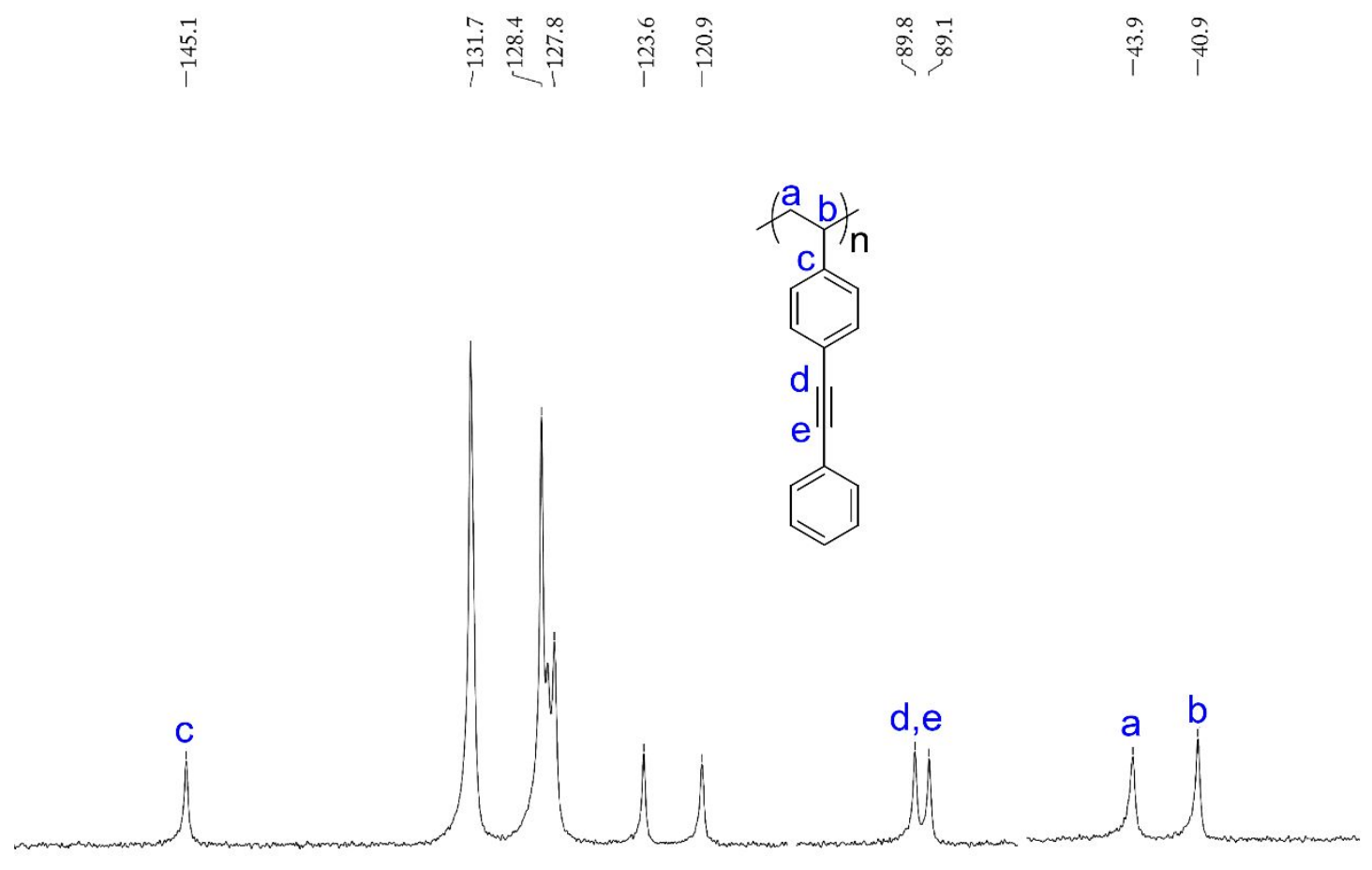

$\begin{array}{lllllllllllllllllllllllllllllll}152 & 150 & 148 & 146 & 144 & 142 & 140 & 138 & 136 & 134 & 132 & 130 & 128 & 126 & 124 & 122 & 120 & 118 & 94 & 92 & 90 & 88 & 86 & 48 & 46 & 44 & 42 & 40 & 38 & 36 & 34\end{array}$

Figure S5. ${ }^{13} \mathrm{C}$ NMR spectrum of poly(PES) $\left(100 \mathrm{MHz}, \mathrm{CDCl}_{3}, 25{ }^{\circ} \mathrm{C}\right)$ (Table 1 , run 9).

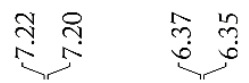
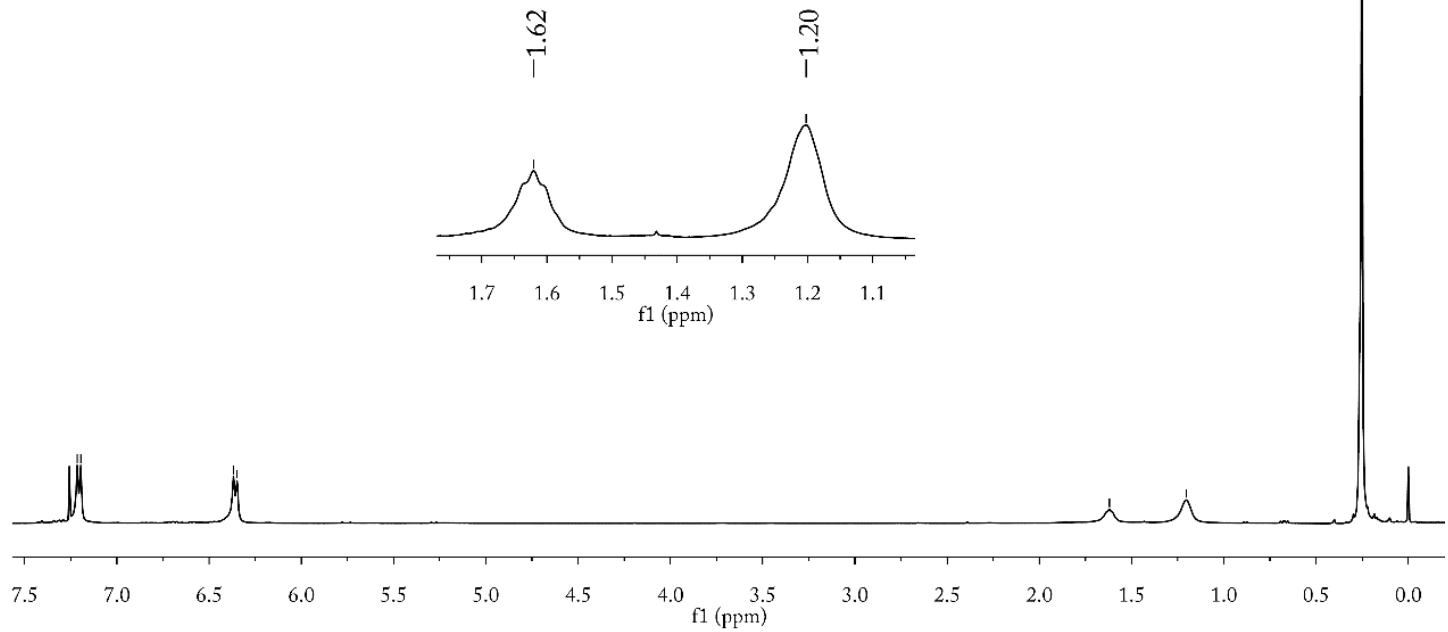

Figure S6. ${ }^{1} \mathrm{H}$ NMR spectrum of poly(TES) $\left(400 \mathrm{MHz}, \mathrm{CDCl}_{3}, 25^{\circ} \mathrm{C}\right)($ Table 1 , run 16). 
年先 $\underbrace{\circ}$

$\begin{array}{lll}\text { กั } & \text { เก } & \text { กิ }\end{array}$
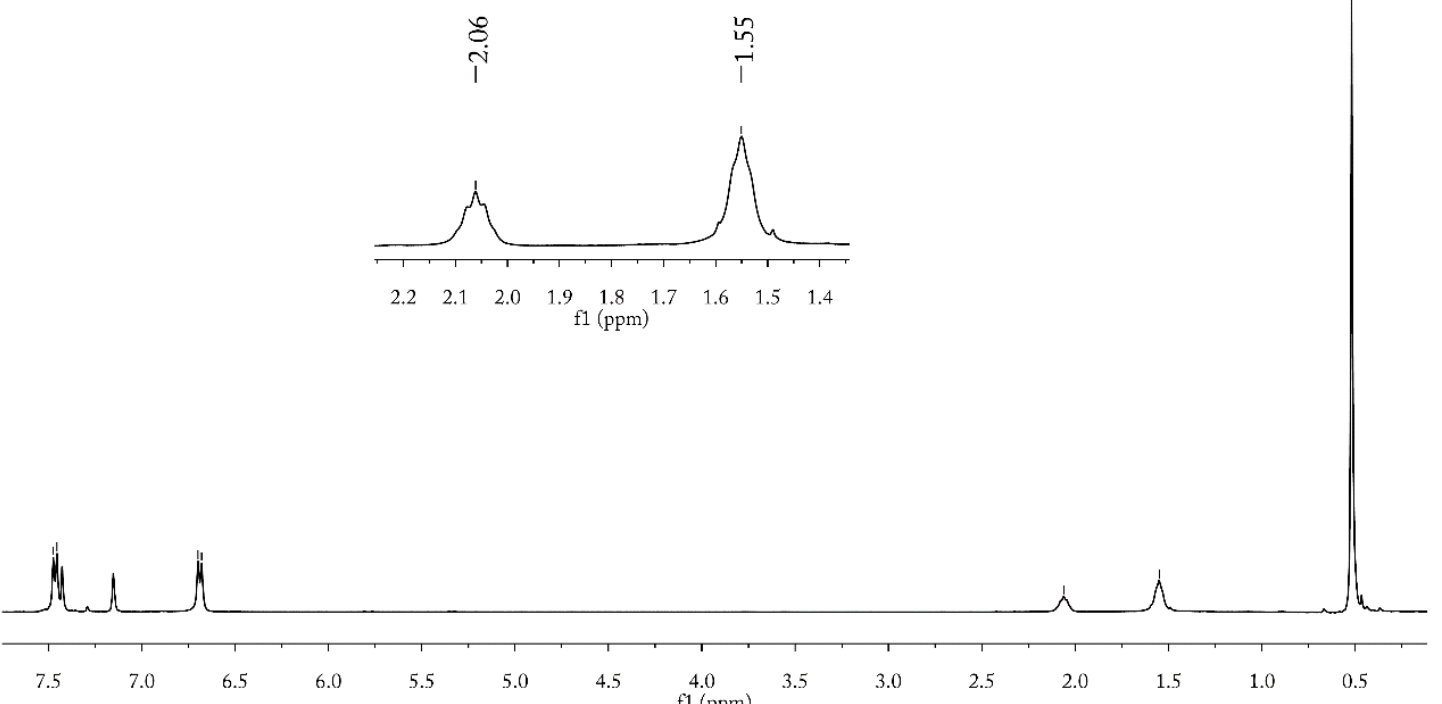

Figure S7. ${ }^{1} \mathrm{H}$ NMR spectrum of poly(TES) $\left(400 \mathrm{MHz}, \mathrm{C}_{6} \mathrm{D}_{2} \mathrm{Cl}_{2}, 110{ }^{\circ} \mathrm{C}\right)$ (Table 1 , run 16).

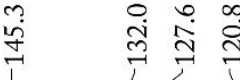
旾
$\stackrel{\circ}{\stackrel{0}{+}} \stackrel{0}{\dot{7}}$

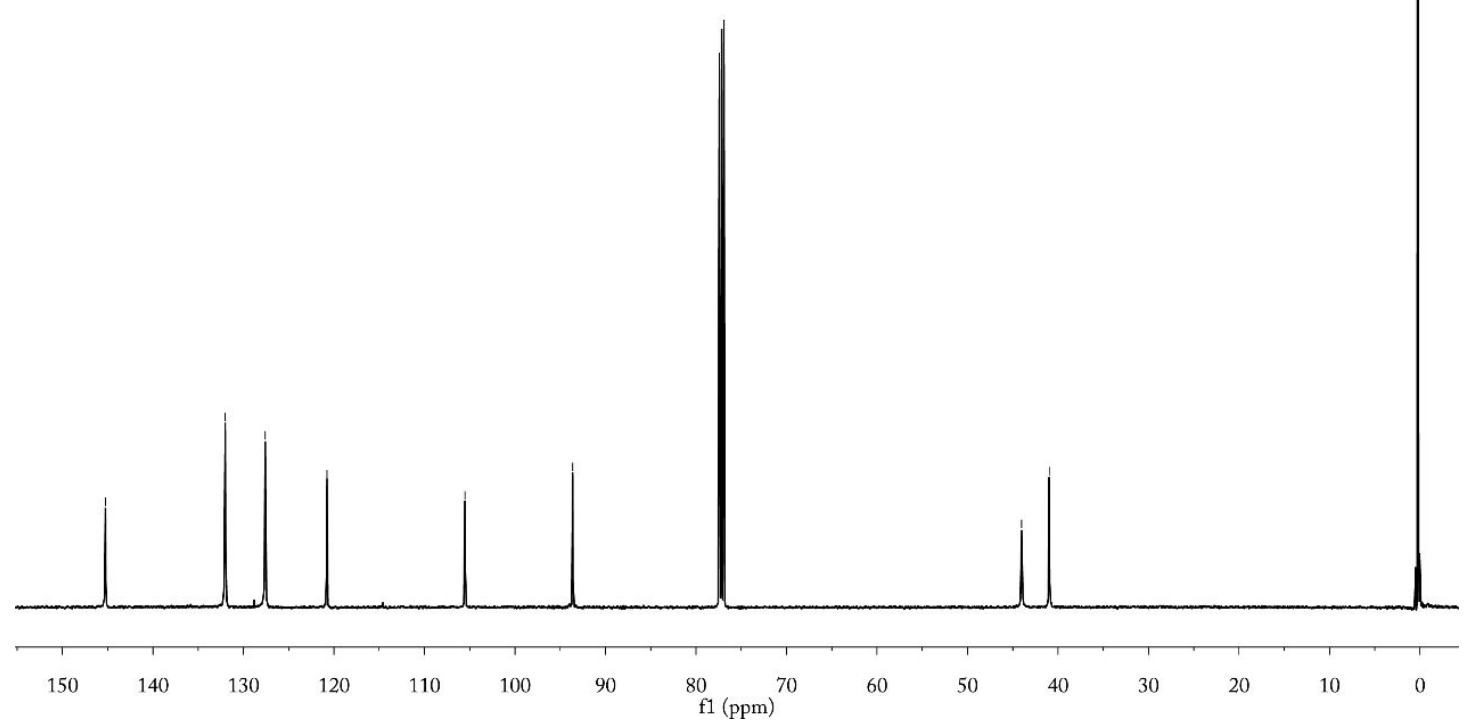

Figure S8. ${ }^{13} \mathrm{C}$ NMR spectra of poly(TES) $\left(100 \mathrm{MHz}, \mathrm{CDCl}_{3}, 25{ }^{\circ} \mathrm{C}\right)$ (Table 1, run 16). 


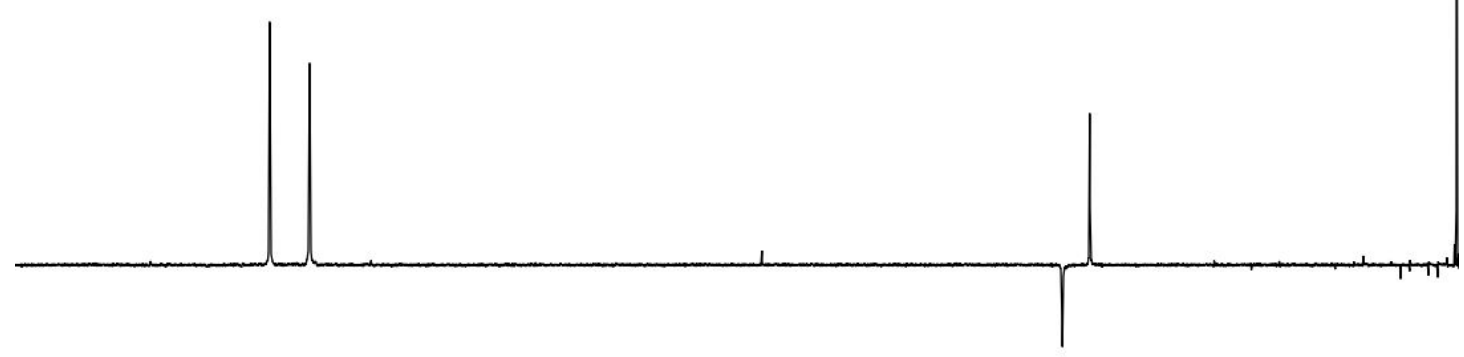

\begin{tabular}{|c|c|c|c|c|c|c|c|c|c|c|c|c|c|c|c|}
\hline 50 & 150 & 140 & 130 & 120 & 110 & 100 & 90 & $\begin{array}{c}80 \\
\mathrm{f} 1(\mathrm{ppm})\end{array}$ & 70 & 60 & 50 & 40 & 30 & 20 & 10 \\
\hline
\end{tabular}

Figure S9. DEPT ${ }^{135} \mathrm{NMR}$ spectrum of poly(TES) $\left(100 \mathrm{MHz}, \mathrm{CDCl}_{3}, 25^{\circ} \mathrm{C}\right)($ Table 1 , run 16).

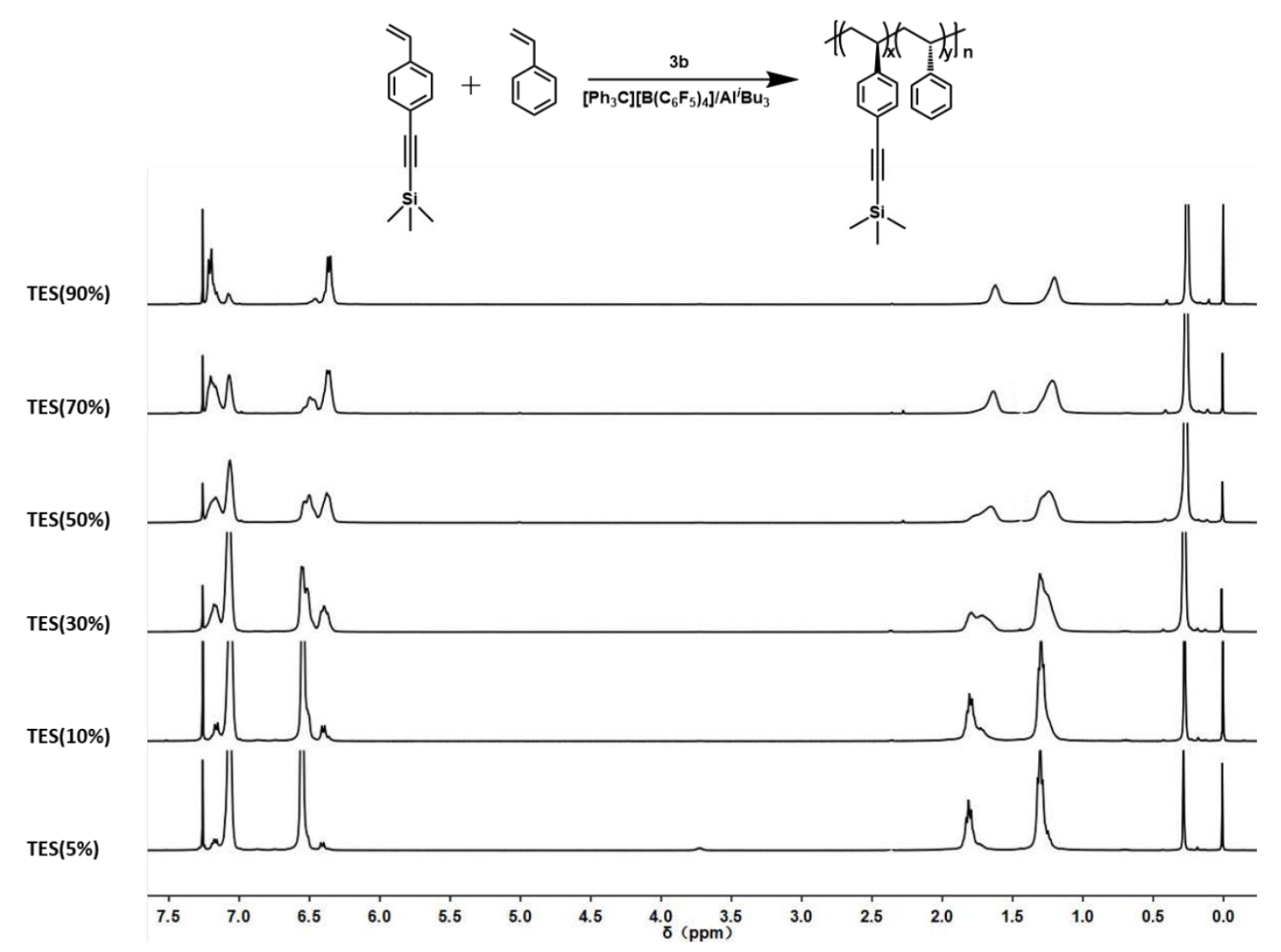

Figure S10. ${ }^{1} \mathrm{H}$ NMR ( $\left.400 \mathrm{MHz}, \mathrm{CDCl}_{3}, 25{ }^{\circ} \mathrm{C}\right)$ spectrum of copolymers with different TES contents. 


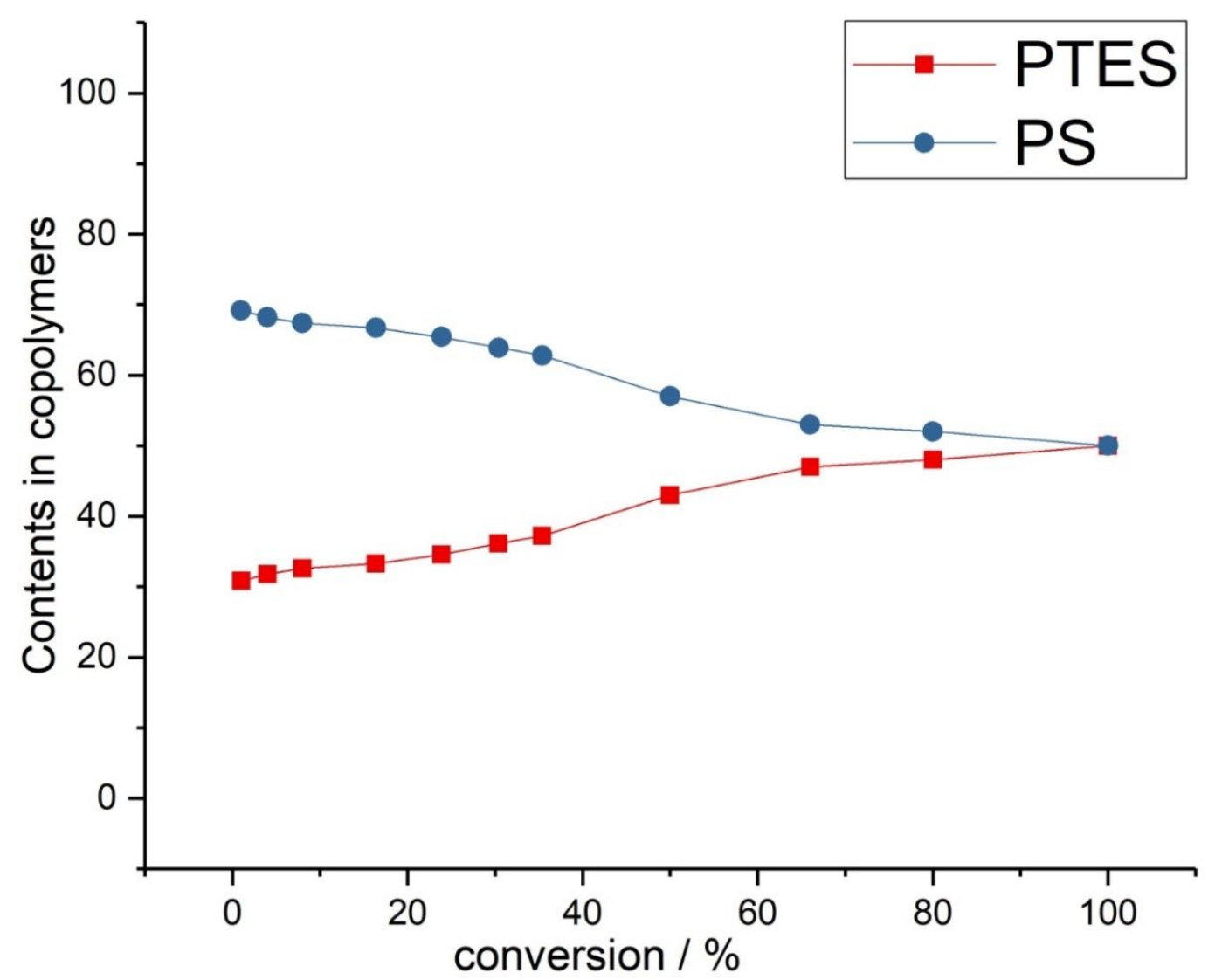

Figure S11. Plots of the contents of poly(TES) (red point) and polystyrene units (blue point $)$ in the copolymers versus the conversions. Complex $\mathbf{3 b}(10 \mu \mathrm{mol}), \mathrm{T}_{\mathrm{p}}=25^{\circ} \mathrm{C}$, $[3 \mathrm{~b}] /\left[\mathrm{Al}^{\mathrm{i}} \mathrm{Bu}_{3}\right] /[\mathrm{B}] /[\mathrm{St}] /[\mathrm{TES}]=1 / 10 / 1 / 300 / 300(\mathrm{~mol} / \mathrm{mol})$.

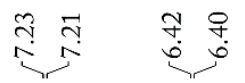

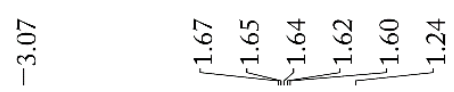

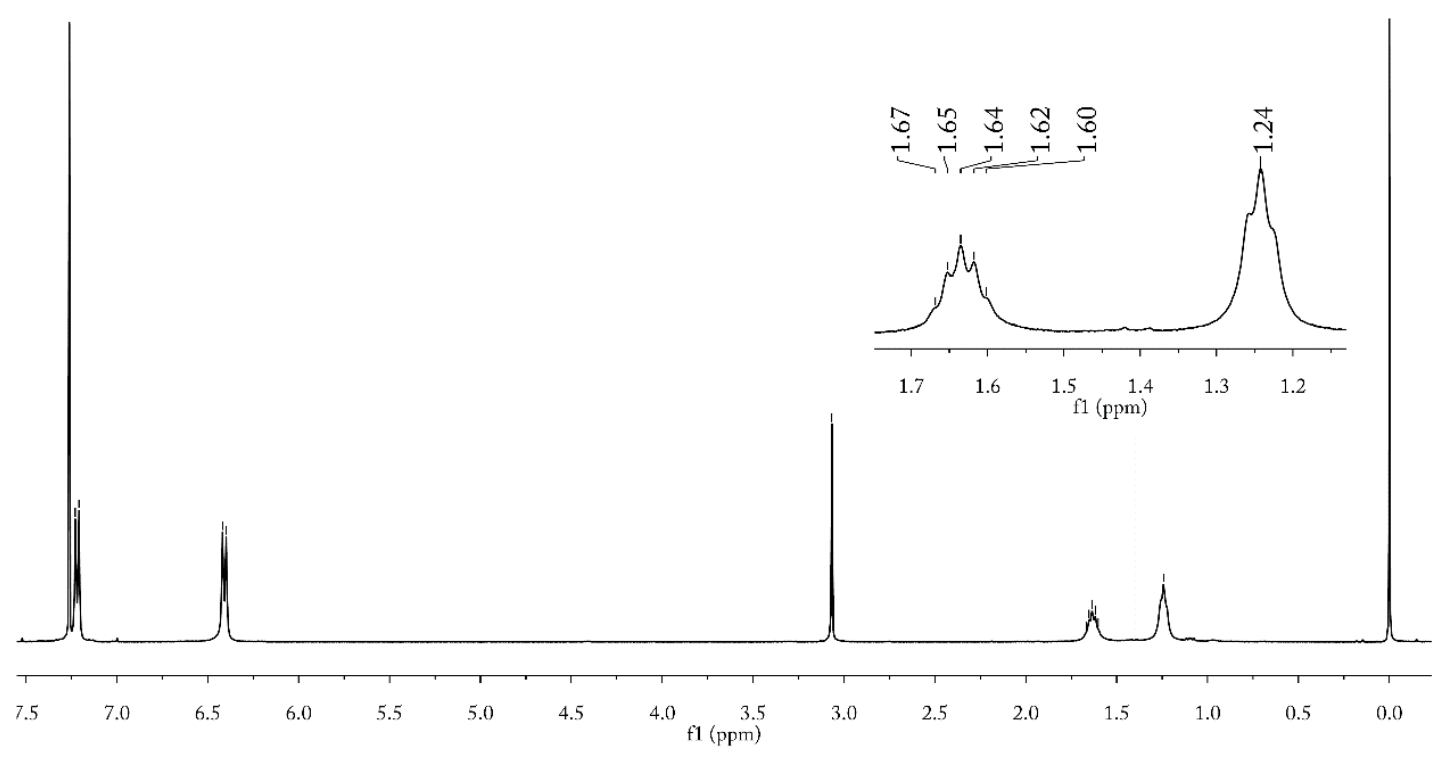

Figure S12. ${ }^{1} \mathrm{H}$ NMR spectrum of poly(ESt) $\left(400 \mathrm{MHz}, \mathrm{CDCl}_{3}, 25^{\circ} \mathrm{C}\right)$. 
醉<smiles>[134IH]</smiles>
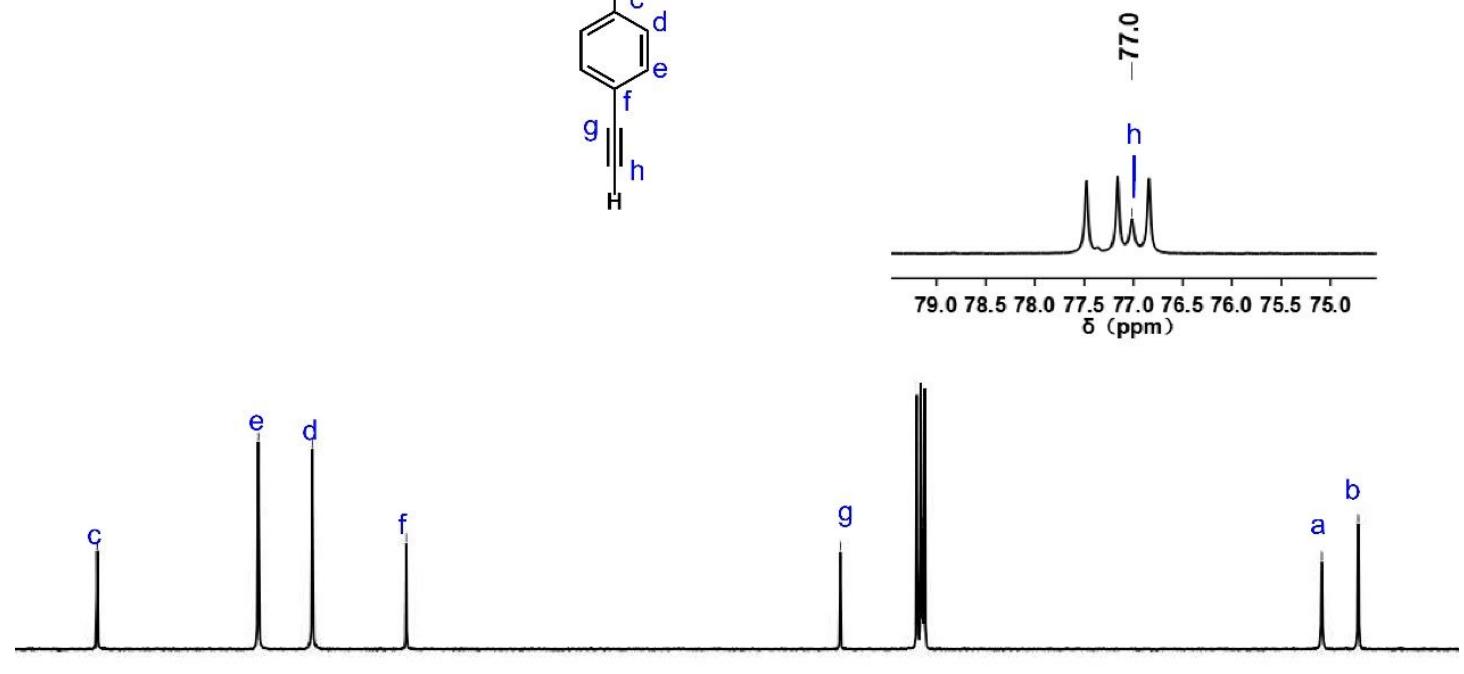

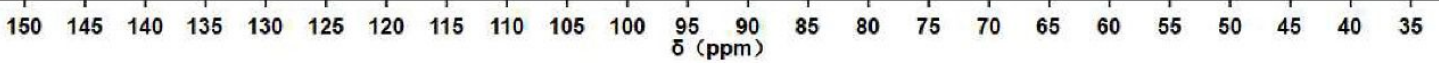

Figure S13. ${ }^{13} \mathrm{C}$ NMR spectrum of poly(ESt) $\left(100 \mathrm{MHz}, \mathrm{CDCl}_{3}, 25{ }^{\circ} \mathrm{C}\right)$.



Figure S14. ${ }^{1} \mathrm{H}$ NMR spectrum of 1-azido-2-methoxybenzene functionalized poly(ESt) $\left(400 \mathrm{MHz}, \mathrm{CDCl}_{3}, 25^{\circ} \mathrm{C}\right)$. 

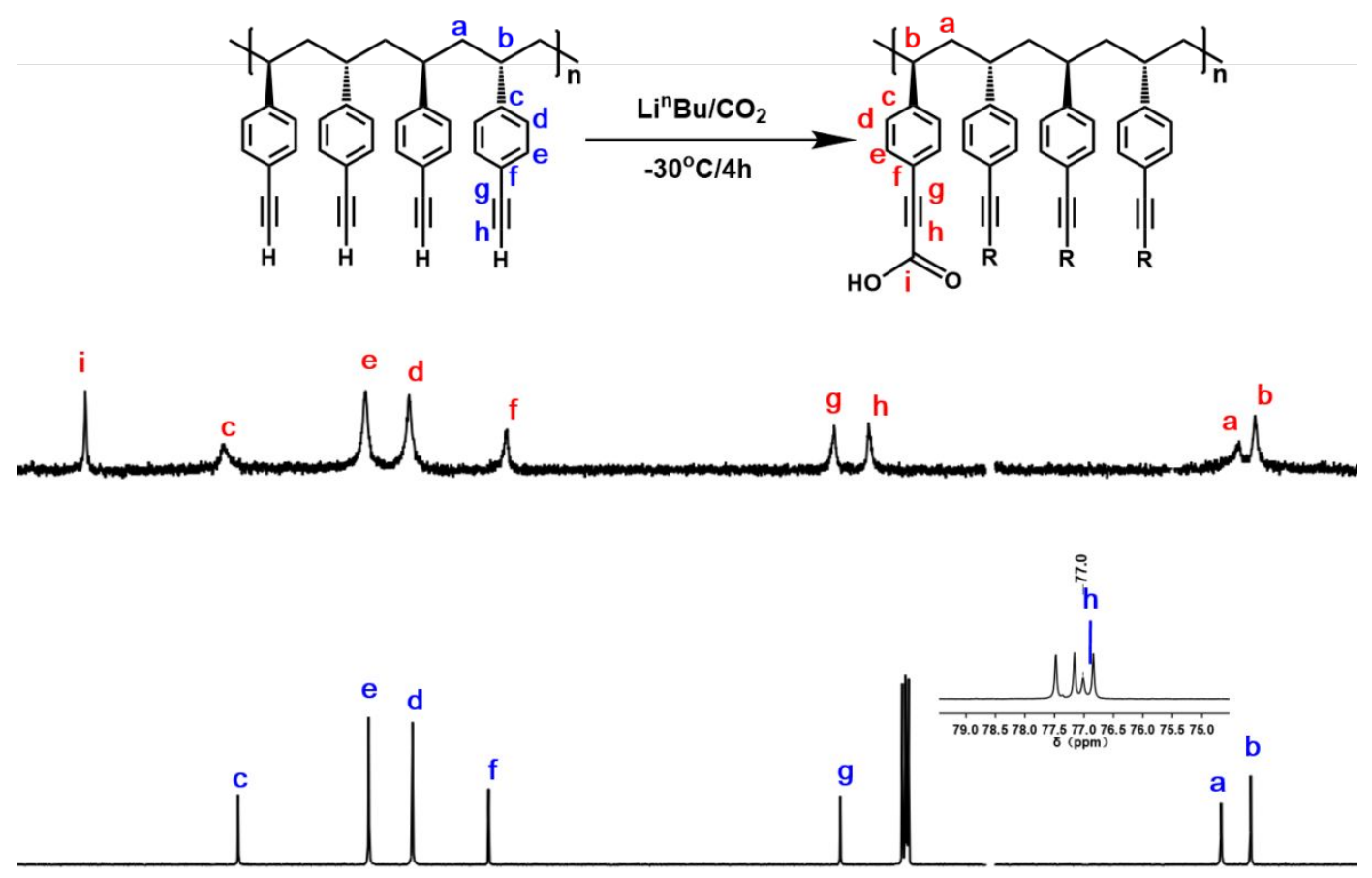

$\begin{array}{llllllllllllllllllllllllllllll}165 & 160 & 155 & 150 & 145 & 140 & 135 & 130 & 125 & 120 & 115 & 110 & 105 & \begin{array}{c}100 \\ 0 \\ (\mathrm{ppm})\end{array} & 95 & 95 & 80 & 75 & 70 & 65 & 60 & 55 & 50 & 45 & 40 & 35 & 31\end{array}$

Figure S15. ${ }^{13} \mathrm{C}$ NMR spectrum of $\mathrm{CO}_{2}$ functionalized poly(ESt) $\left(100 \mathrm{MHz}, \mathrm{D}_{2} \mathrm{O}\right.$, $\left.25^{\circ} \mathrm{C}\right)$.
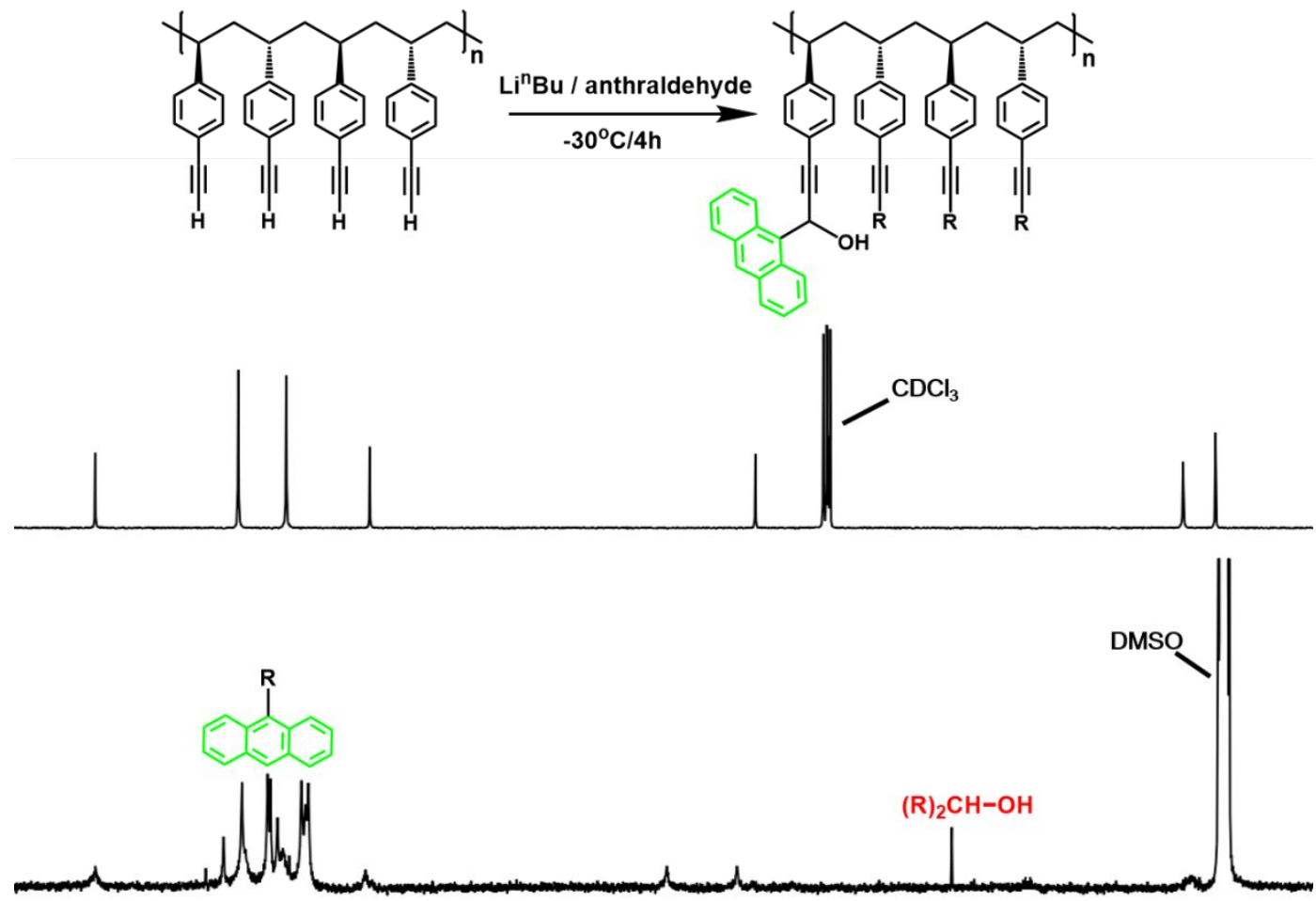

$\begin{array}{lllllllllllllllllllllll}150 & 145 & 140 & 135 & 130 & 125 & 120 & 115 & 110 & 105 & 100 & \begin{array}{c}95 \\ \delta(\mathrm{ppm})\end{array} & 85 & 80 & 75 & 70 & 65 & 60 & 55 & 50 & 45 & 40 & 35\end{array}$

Figure S16. ${ }^{13} \mathrm{C}$ NMR spectrum of anthraldehyde functionalized poly(ESt) (100 $\left.\mathrm{MHz}, \mathrm{DMSO}, 25^{\circ} \mathrm{C}\right)$. 
— anthraldehyde functionalized poly(ES)

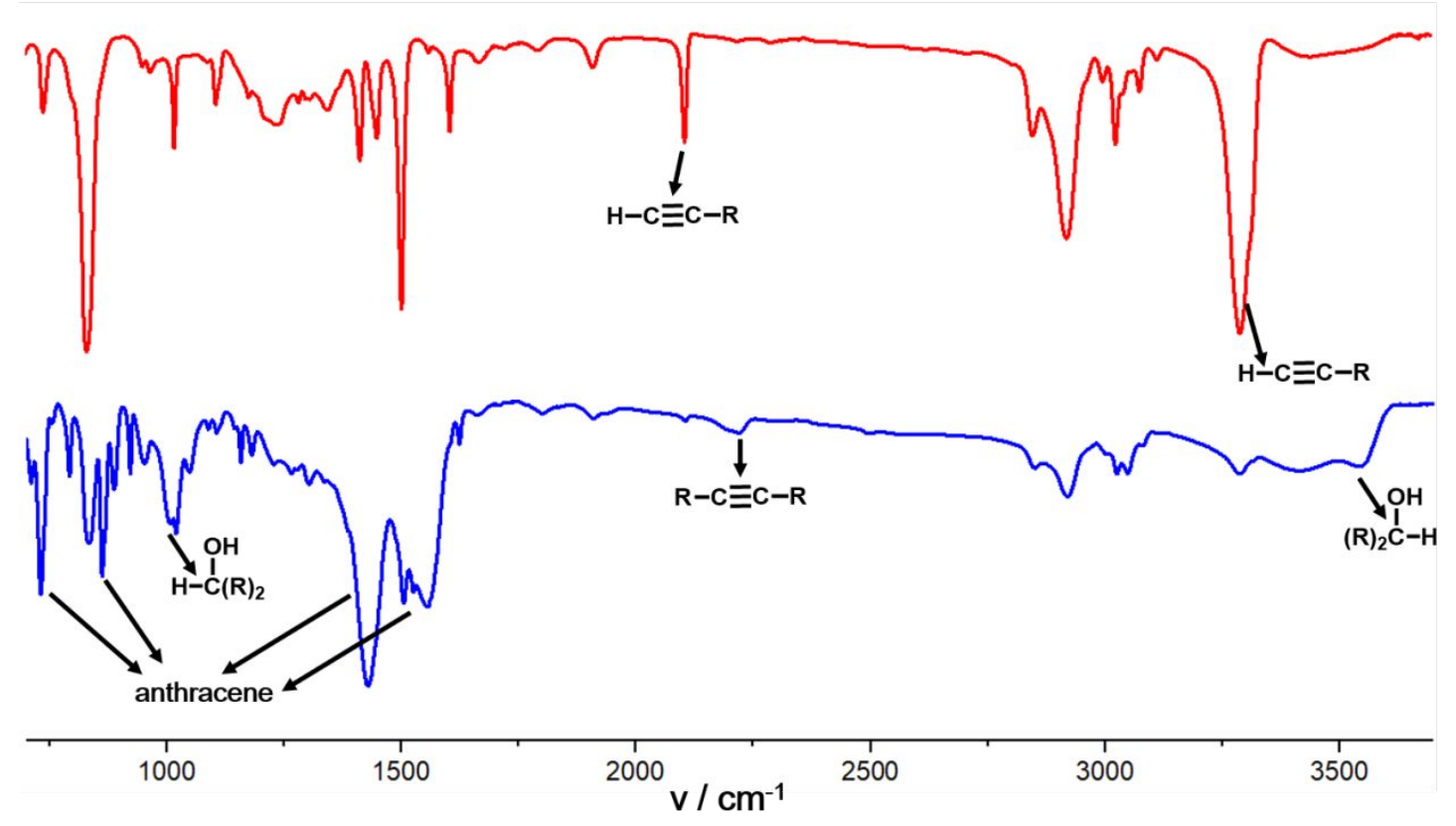

Figure S17. FTIR stack plots of poly(ESt) (red) and anthraldehyde functionalized poly(ES) (blue).
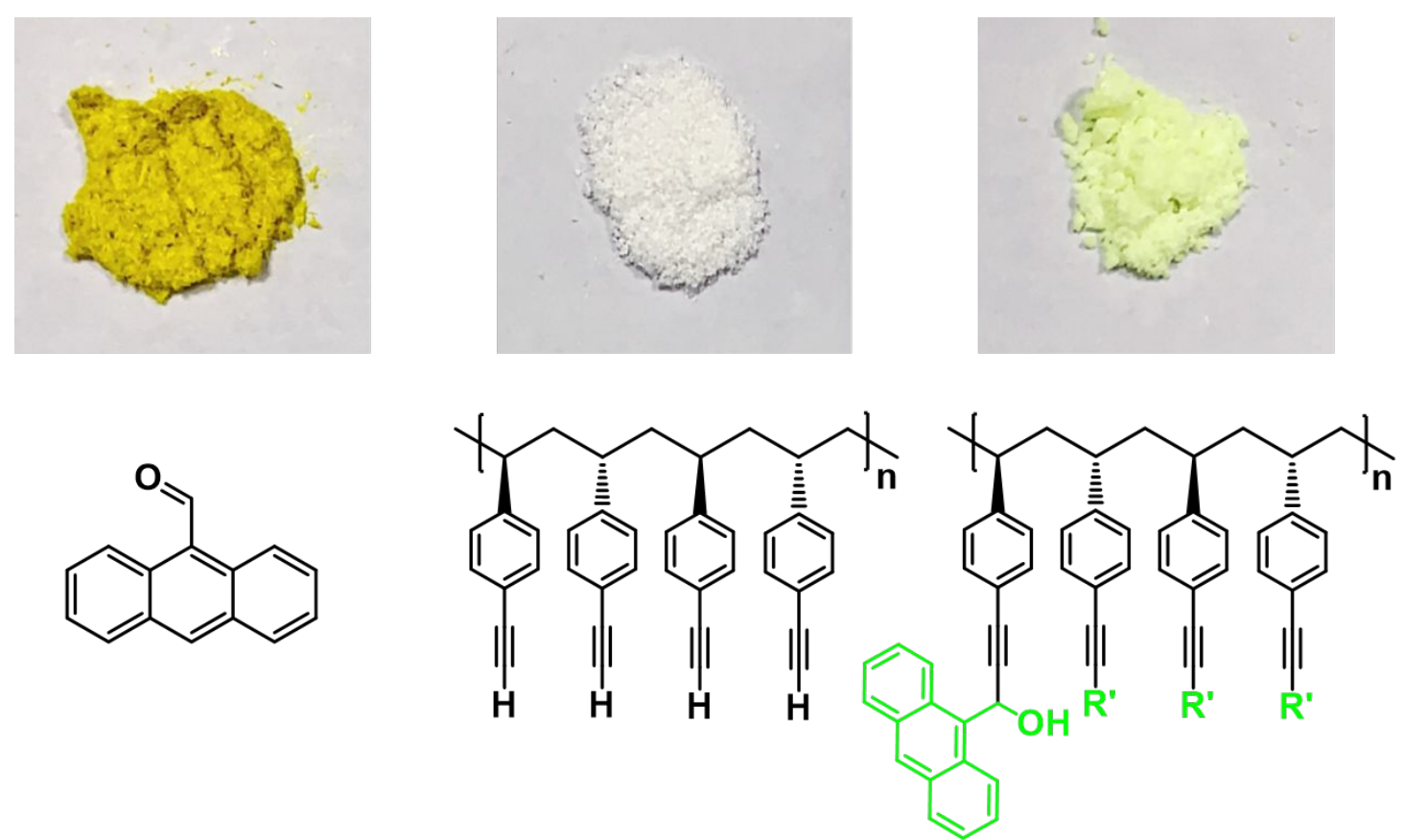

Figure S18A. The anthraldehyde functionalized poly(ESt) in sunlight. 

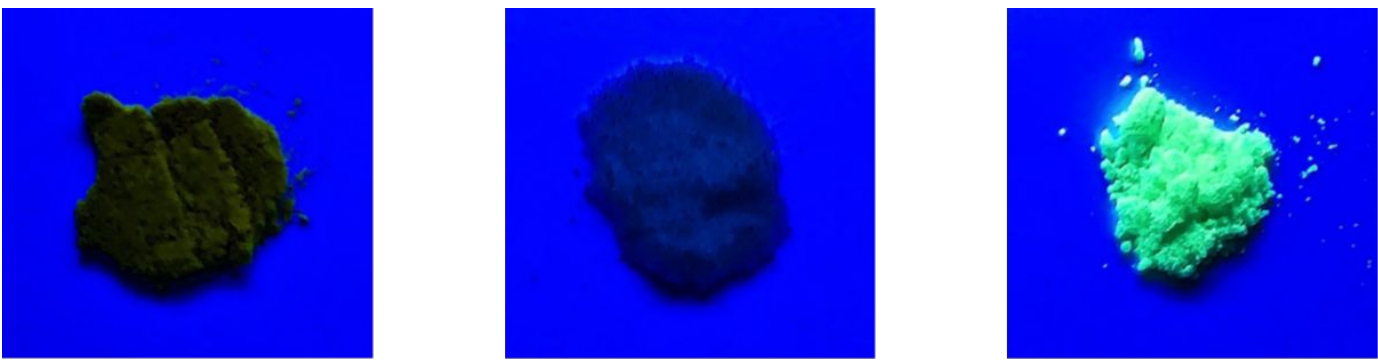<smiles>O=Cc1c2ccccc2cc2ccccc12</smiles>



Figure S18B. The anthraldehyde functionalized poly(ESt) in UV-light(365 nm).

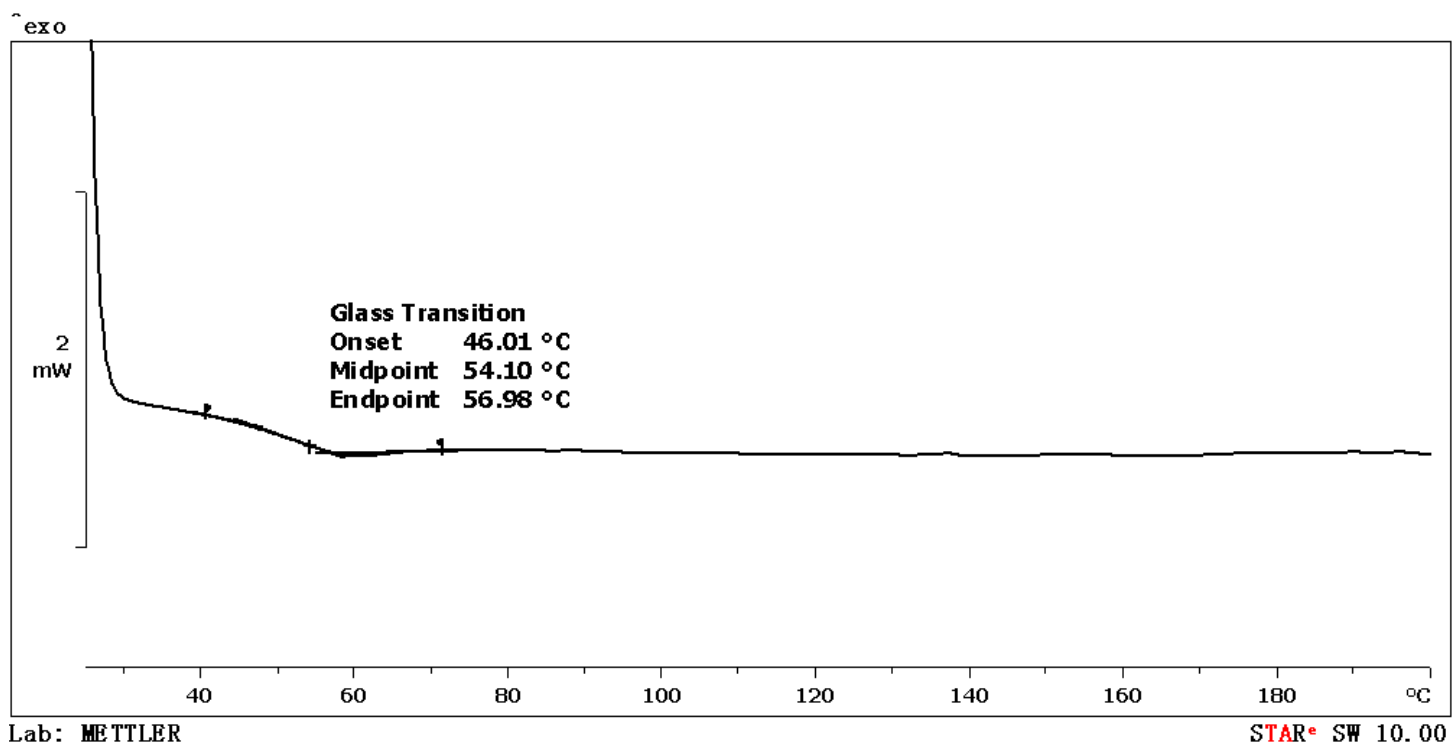

Figure S19. DSC curve of poly(HES) (Table 1, run 2) 


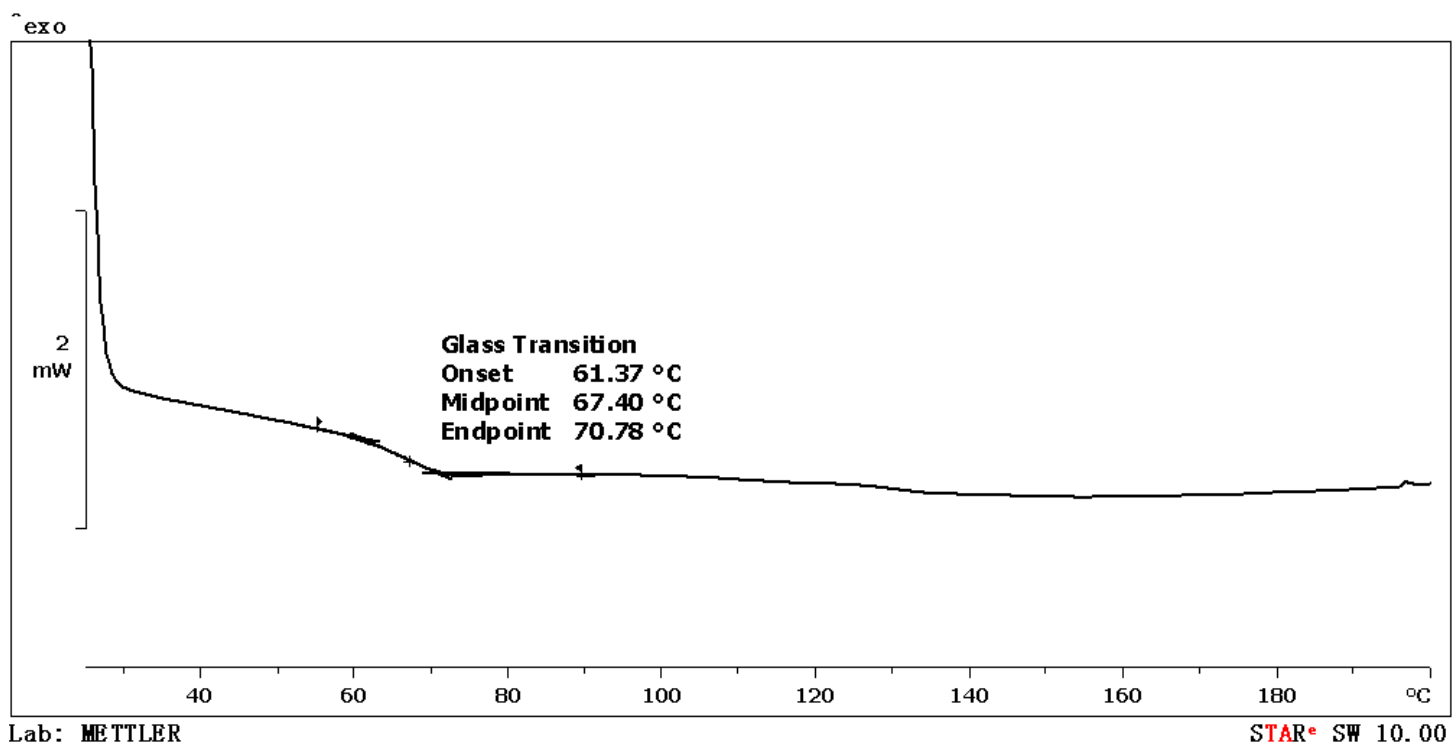

Figure S20. DSC curve of poly(HES) (Table 1, run 3)

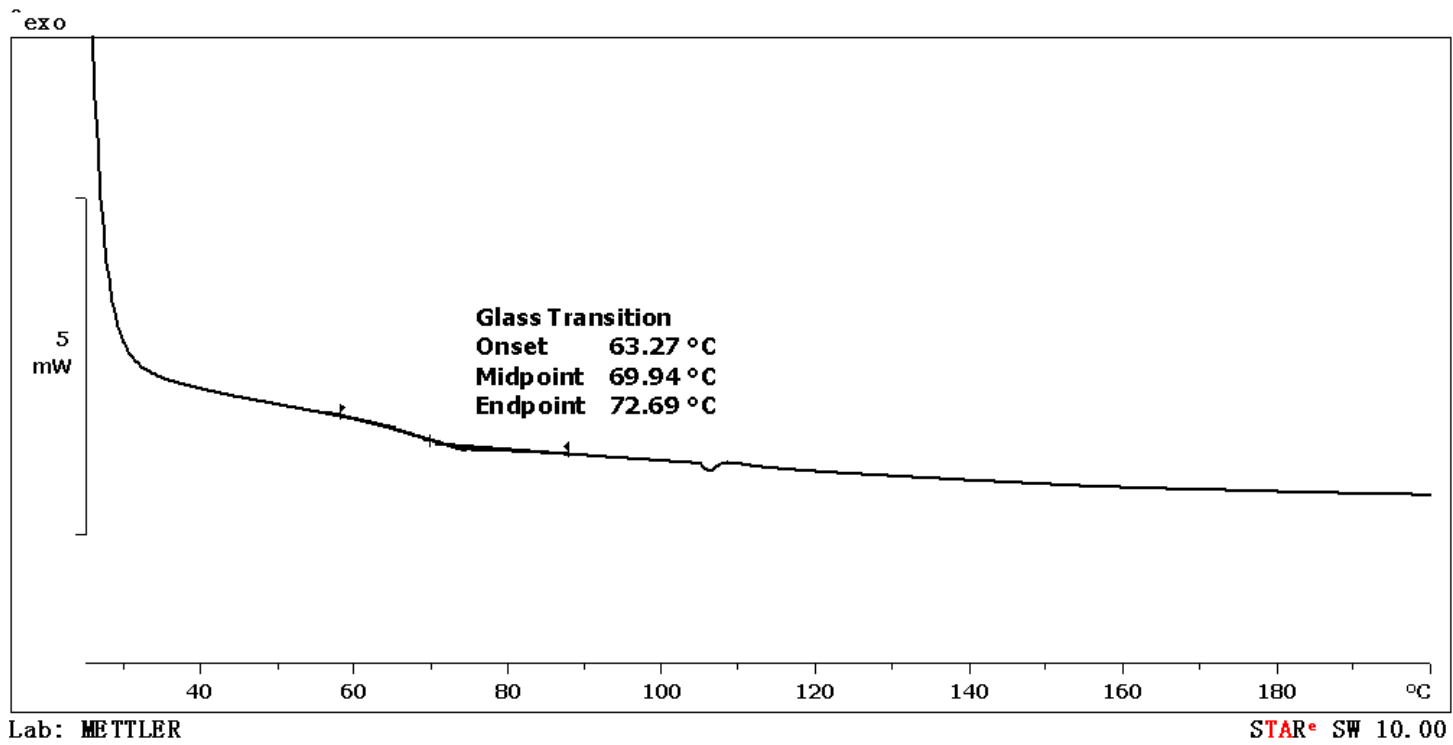

Figure S21. DSC curve of poly(HES) (Table 1, run 4) 


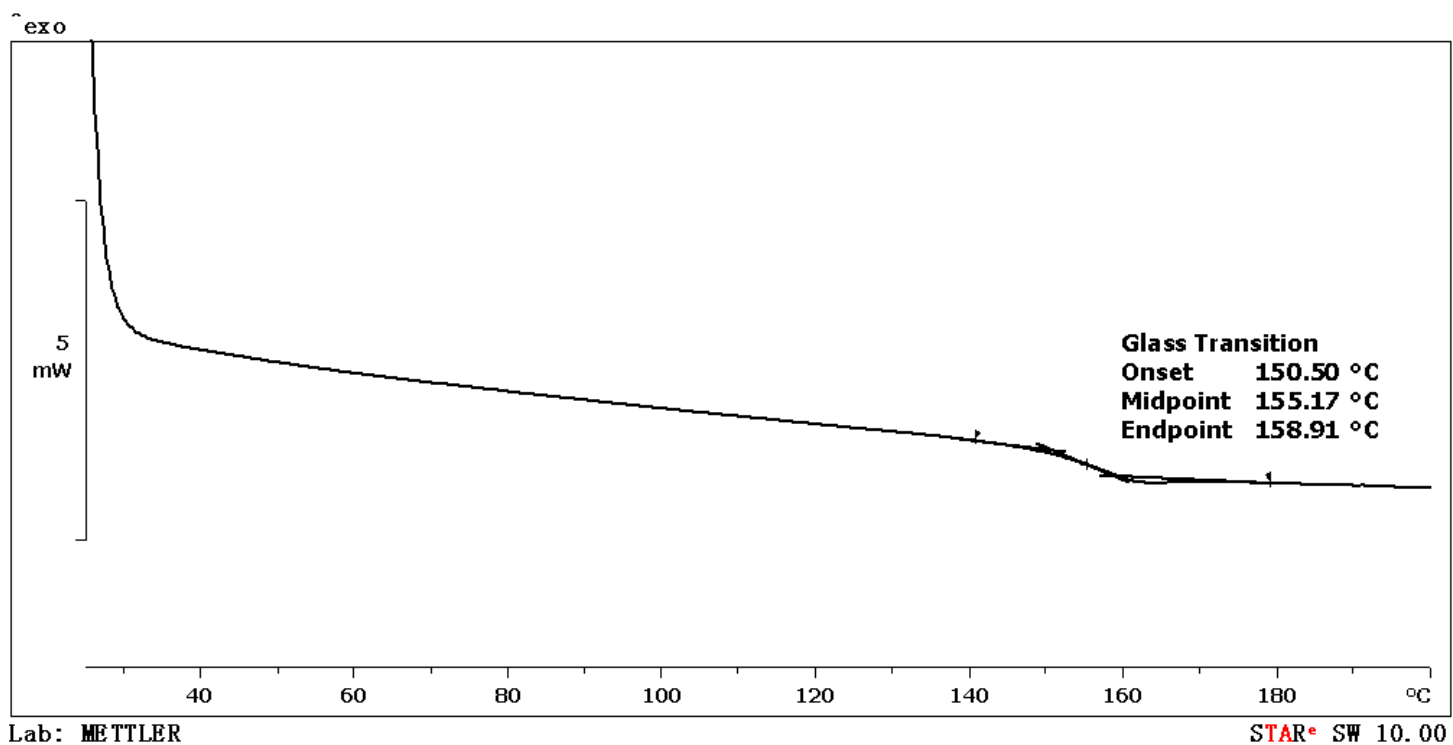

Figure S22. DSC curve of poly(PES) (Table 1, run 5)

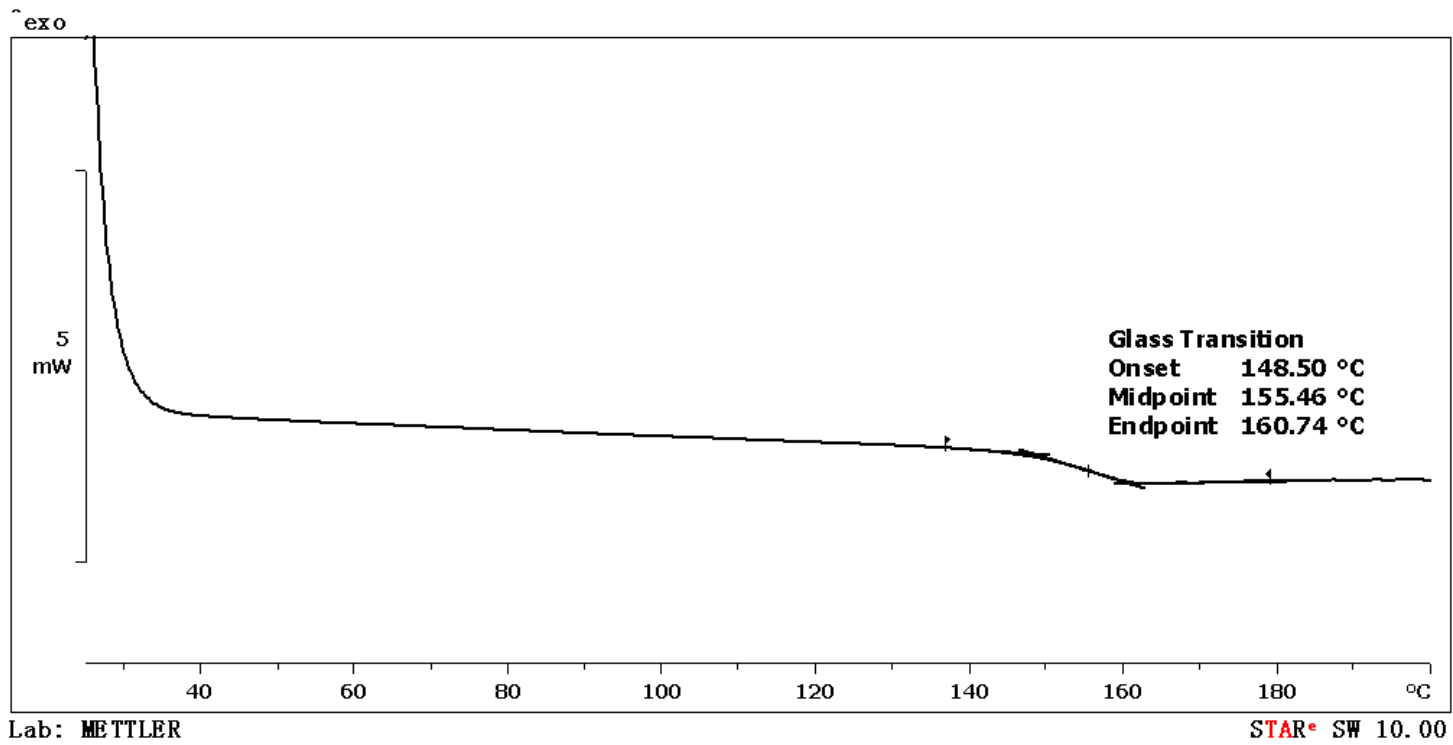

Figure S23. DSC curve of poly(PES) (Table 1, run 6) 


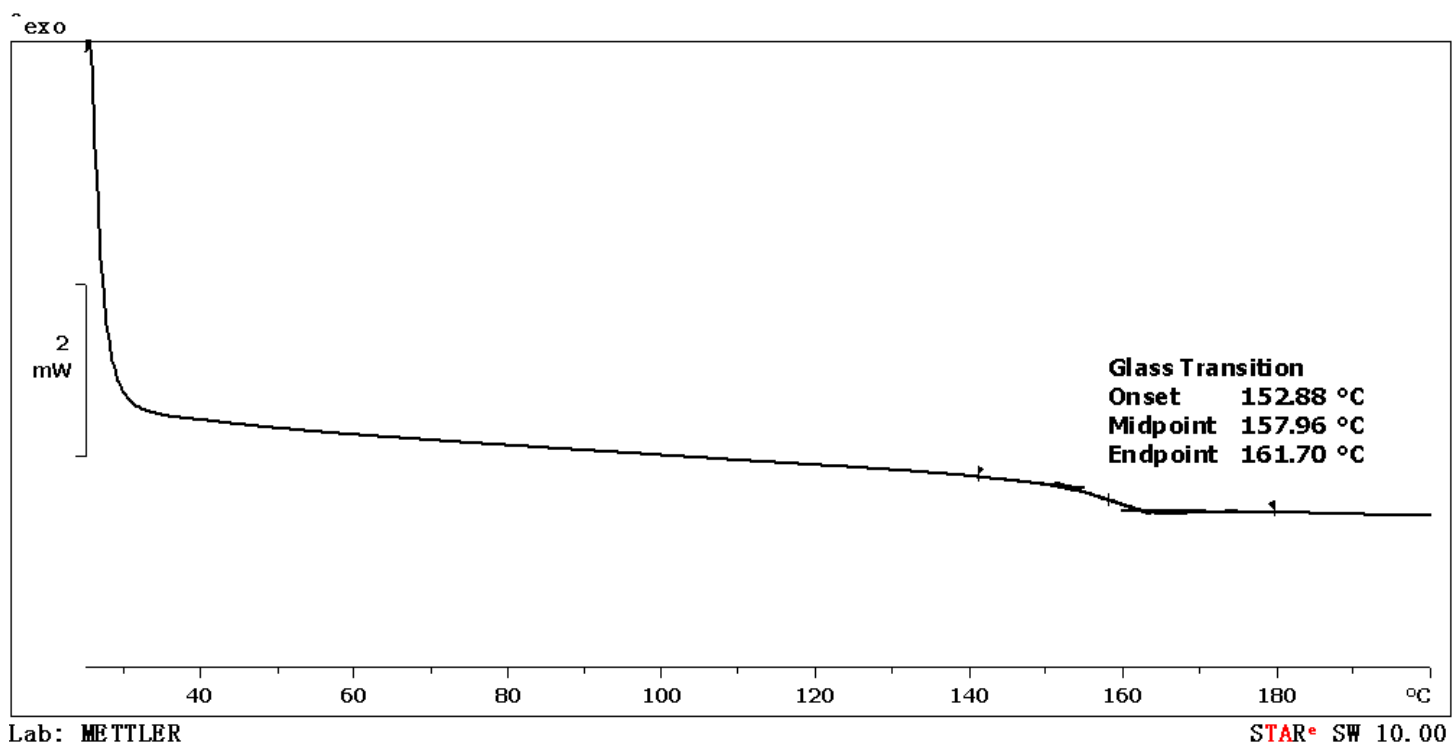

Figure S24. DSC curve of poly(PES) (Table 1, run 7)

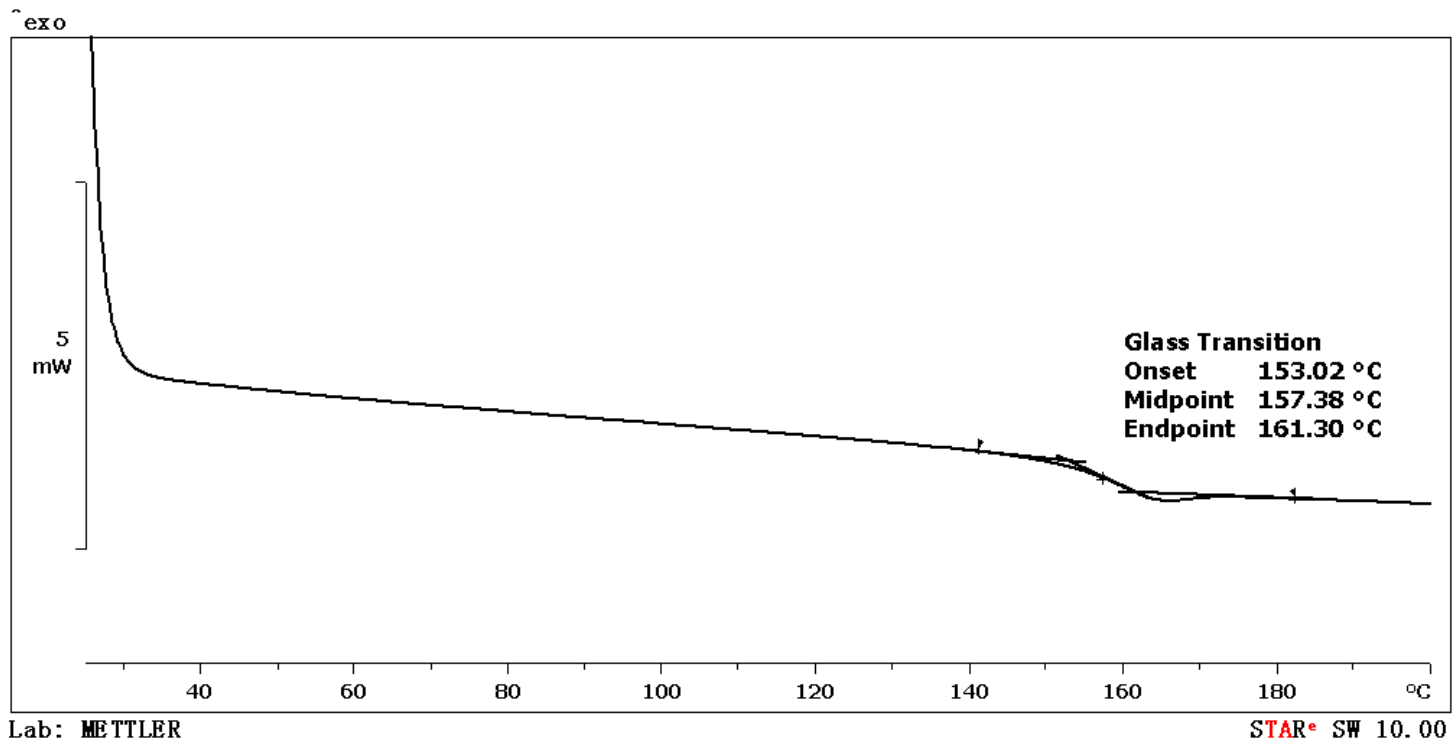

Figure S25. DSC curve of poly(PES) (Table 1, run 8) 


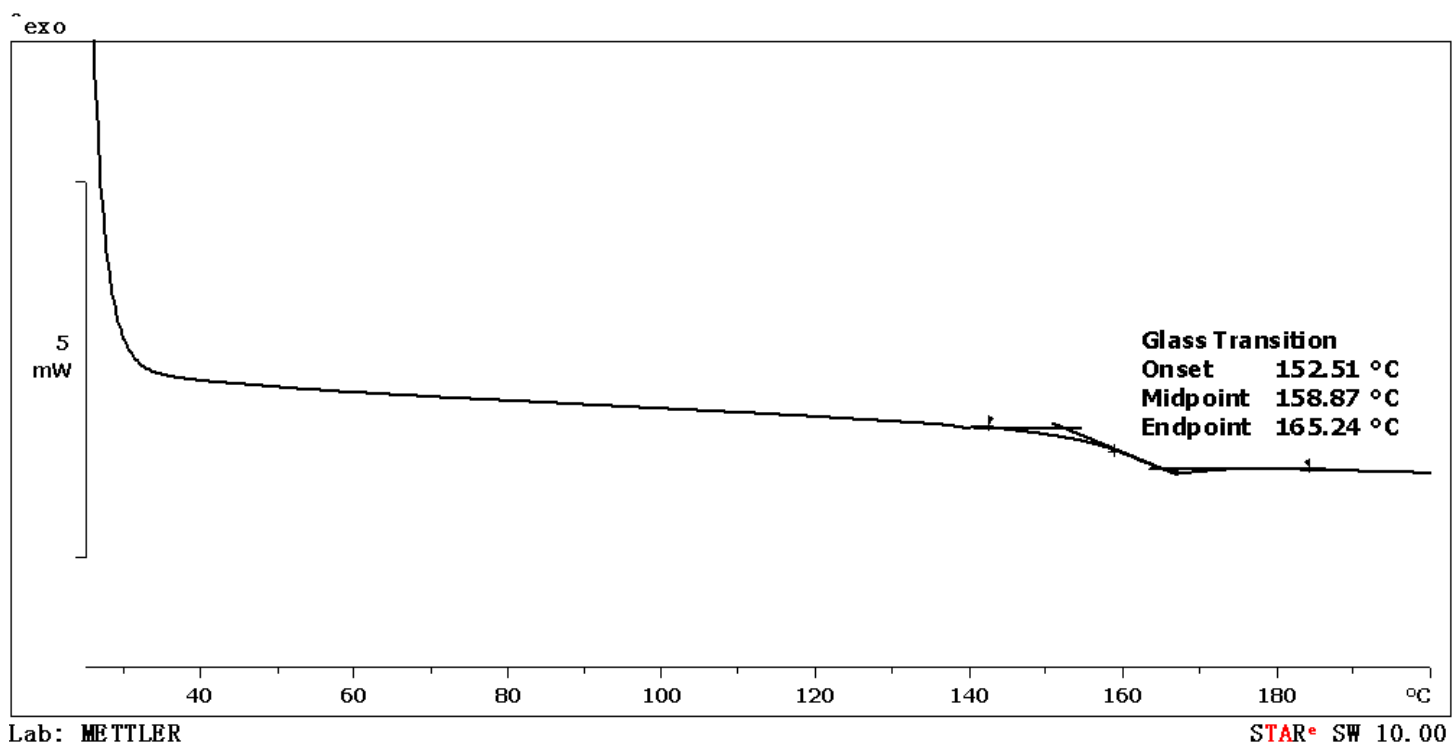

Figure S26. DSC curve of poly(PES) (Table 1, run 9)

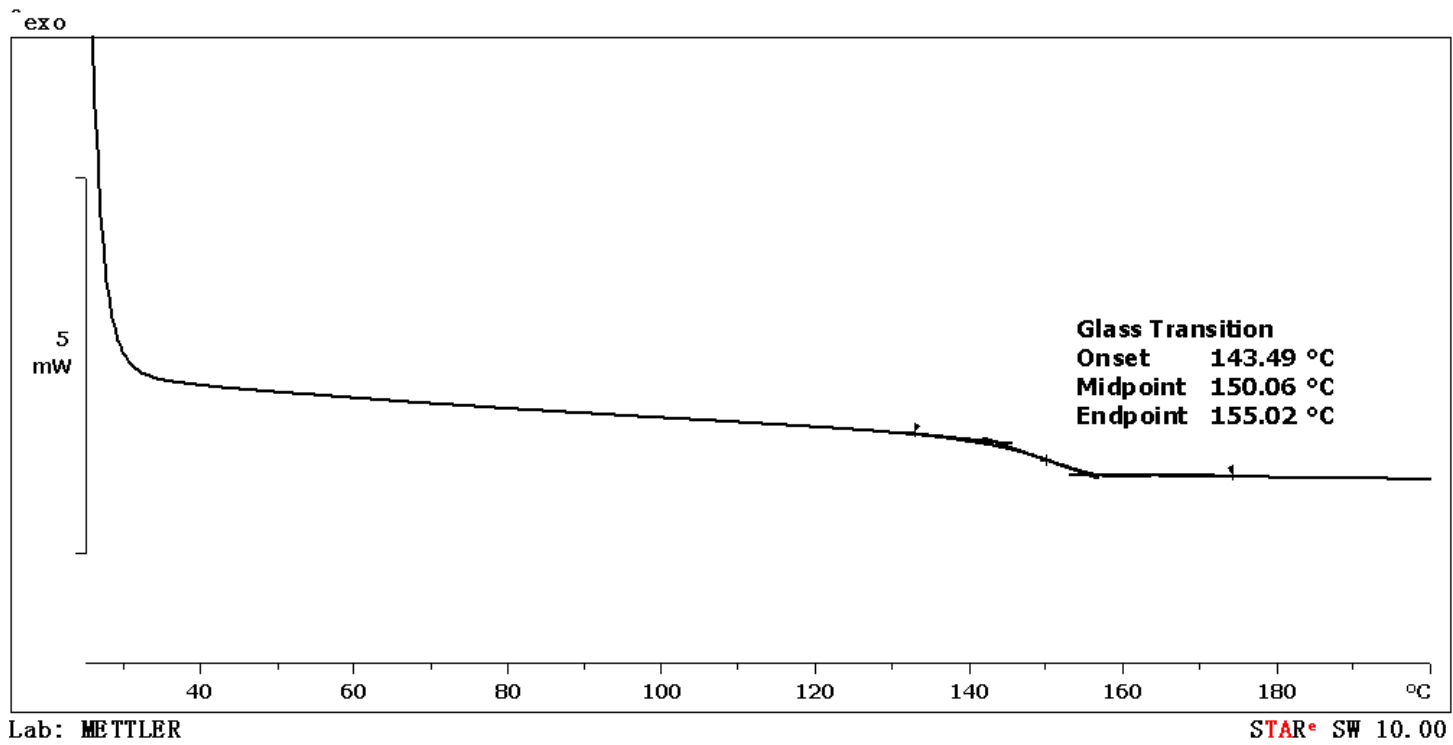

Figure S27. DSC curve of poly(TES) (Table 1, run 10) 


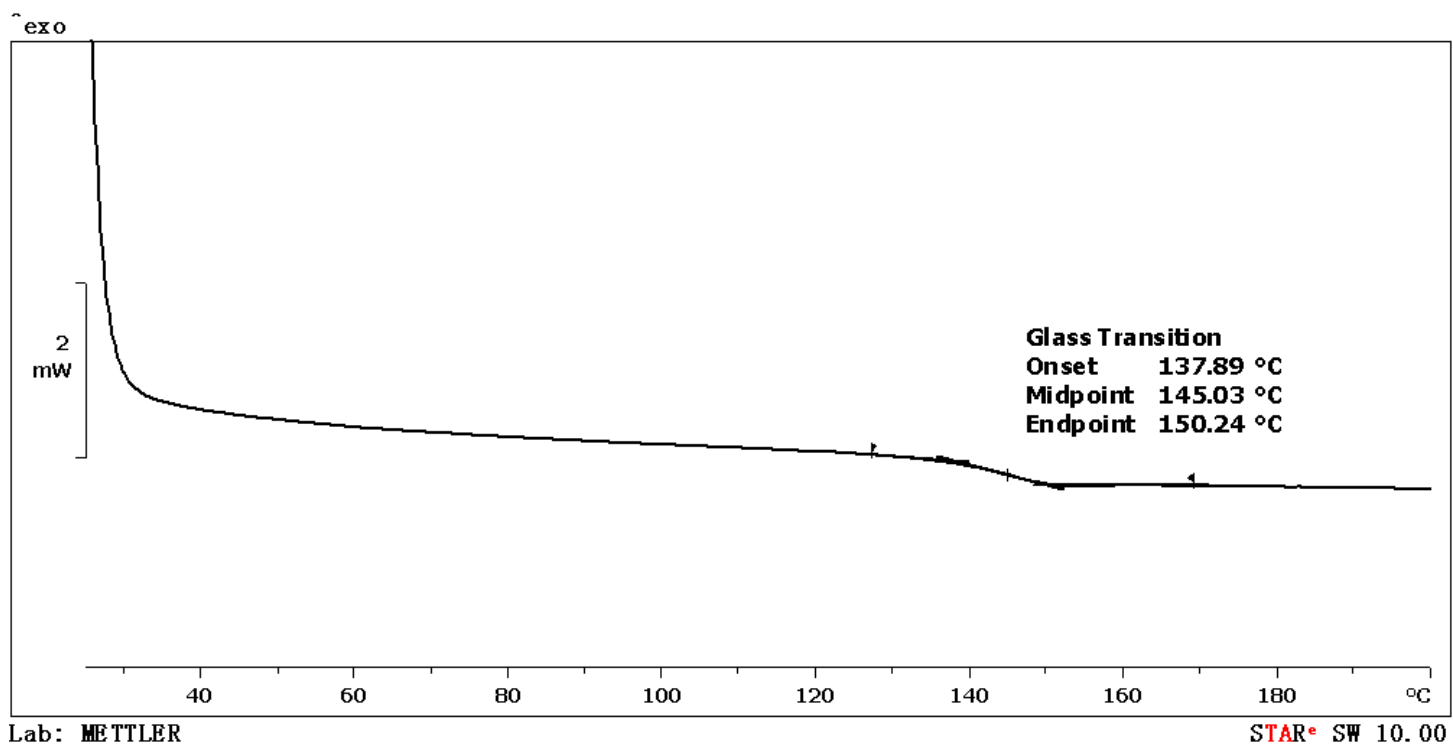

Figure S28. DSC curve of poly(TES) (Table 1, run 12)

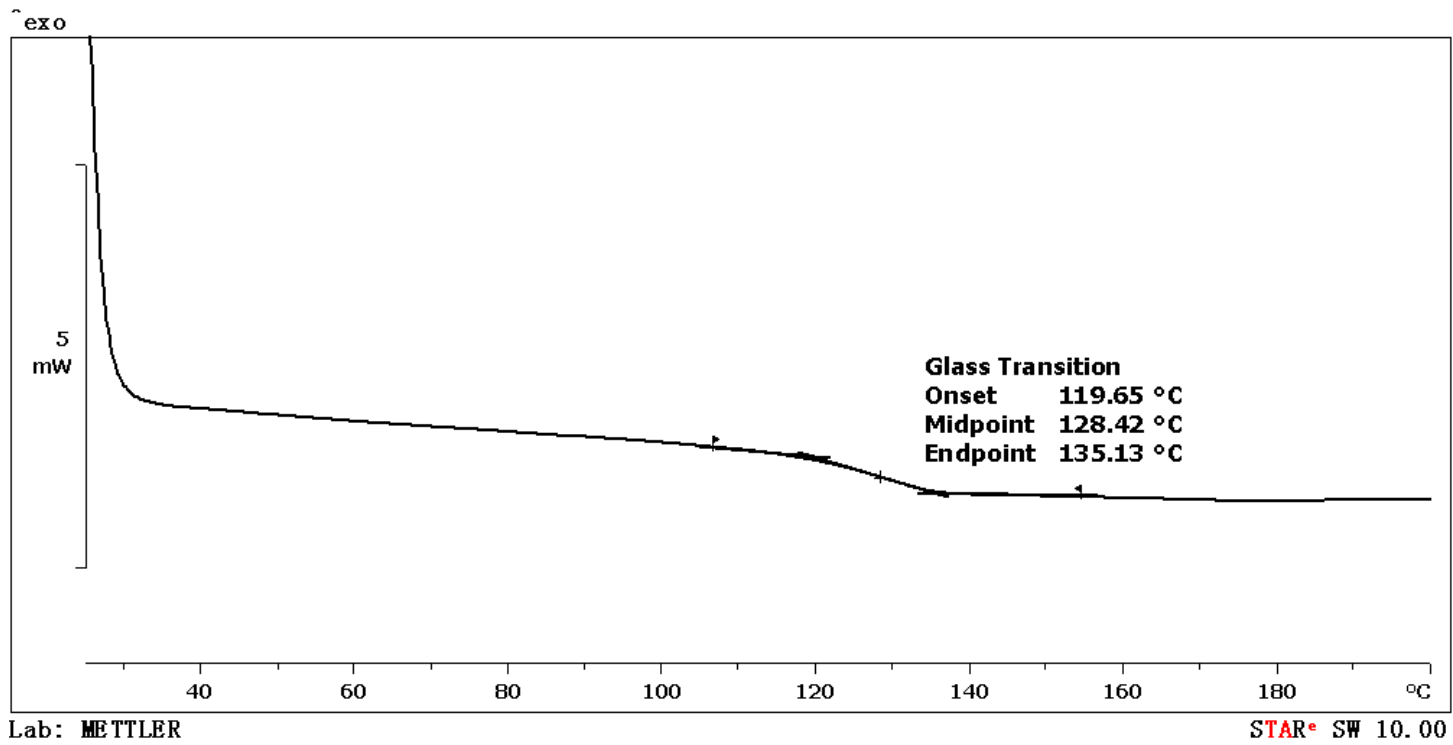

Figure S29. DSC curve of poly(TES) (Table 1, run 13) 


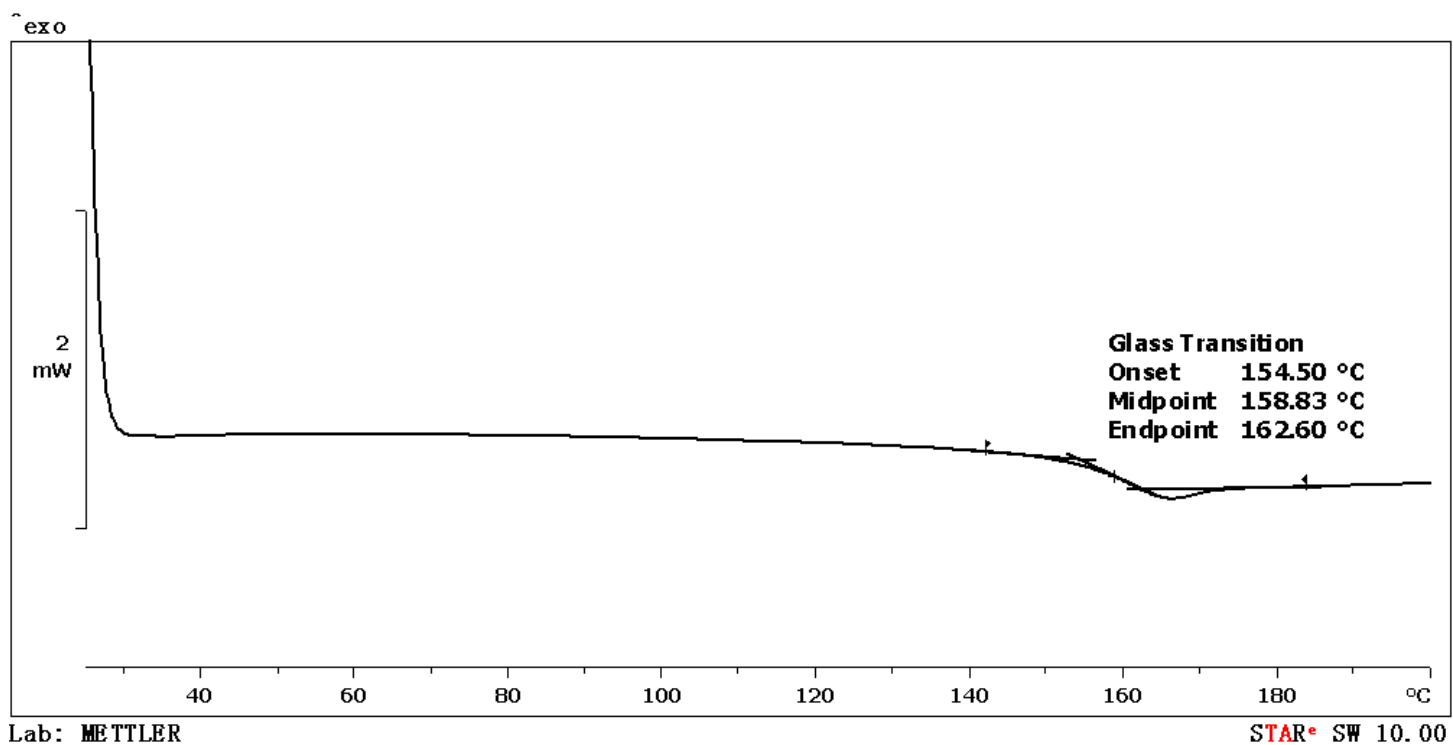

Figure S30. DSC curve of poly(TES) (Table 1, run 14)

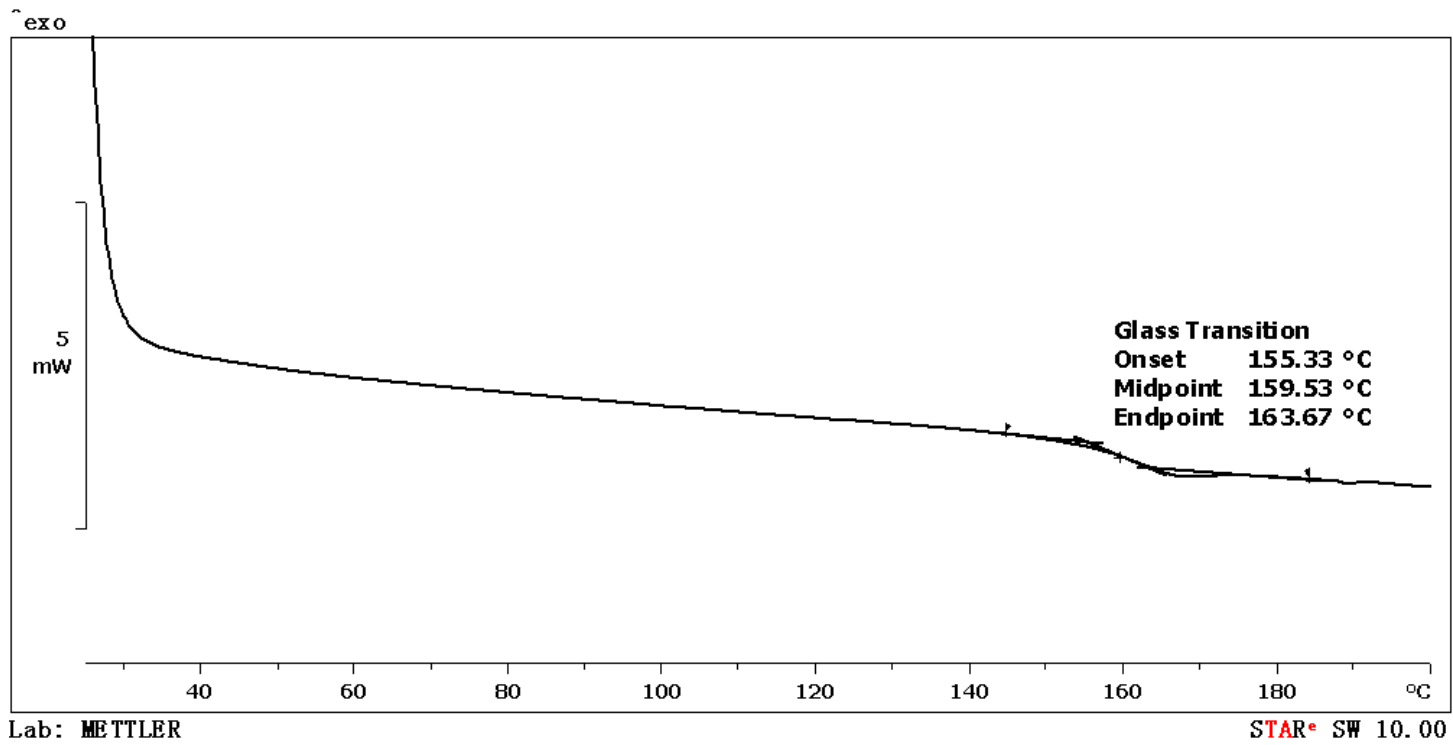

Figure S31. DSC curve of poly(TES) (Table 1, run 15) 


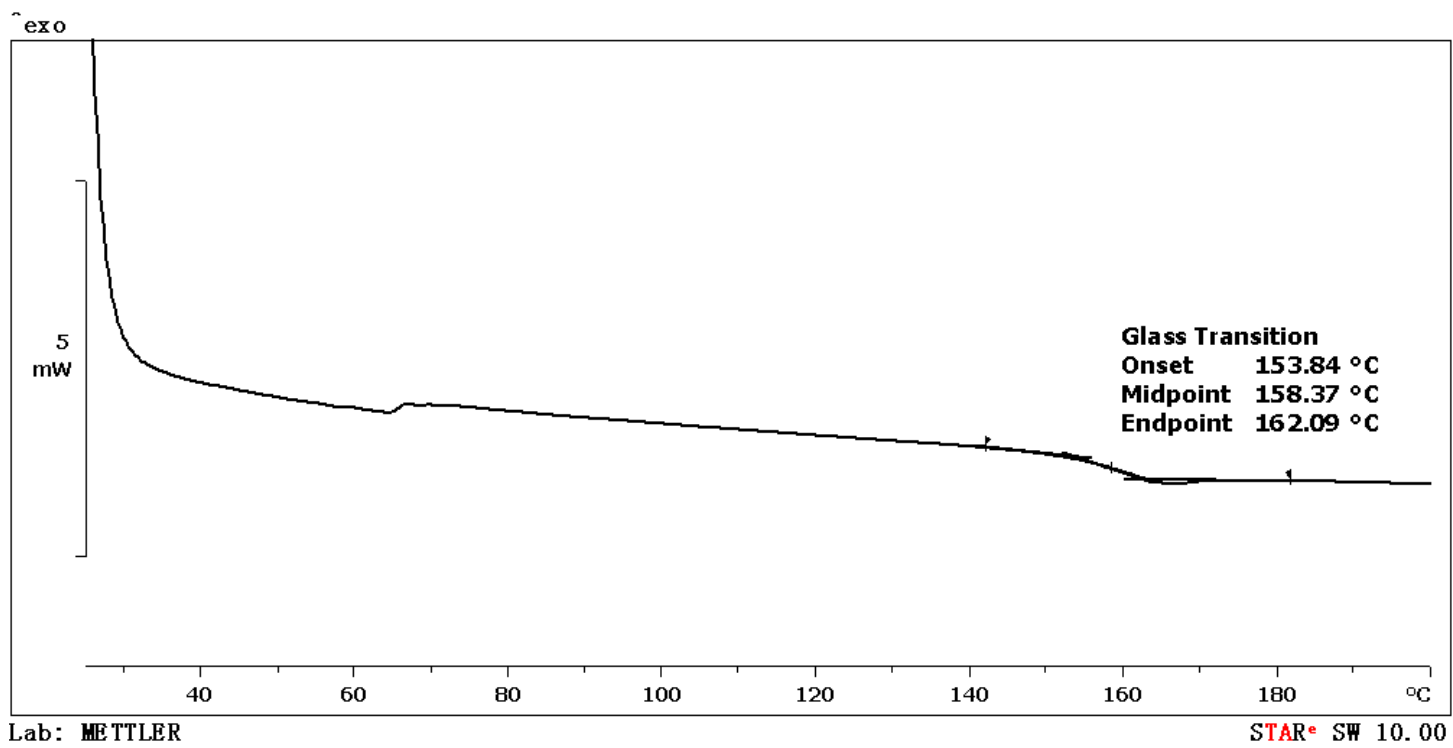

Figure S32. DSC curve of poly(TES) (Table 1, run 16)

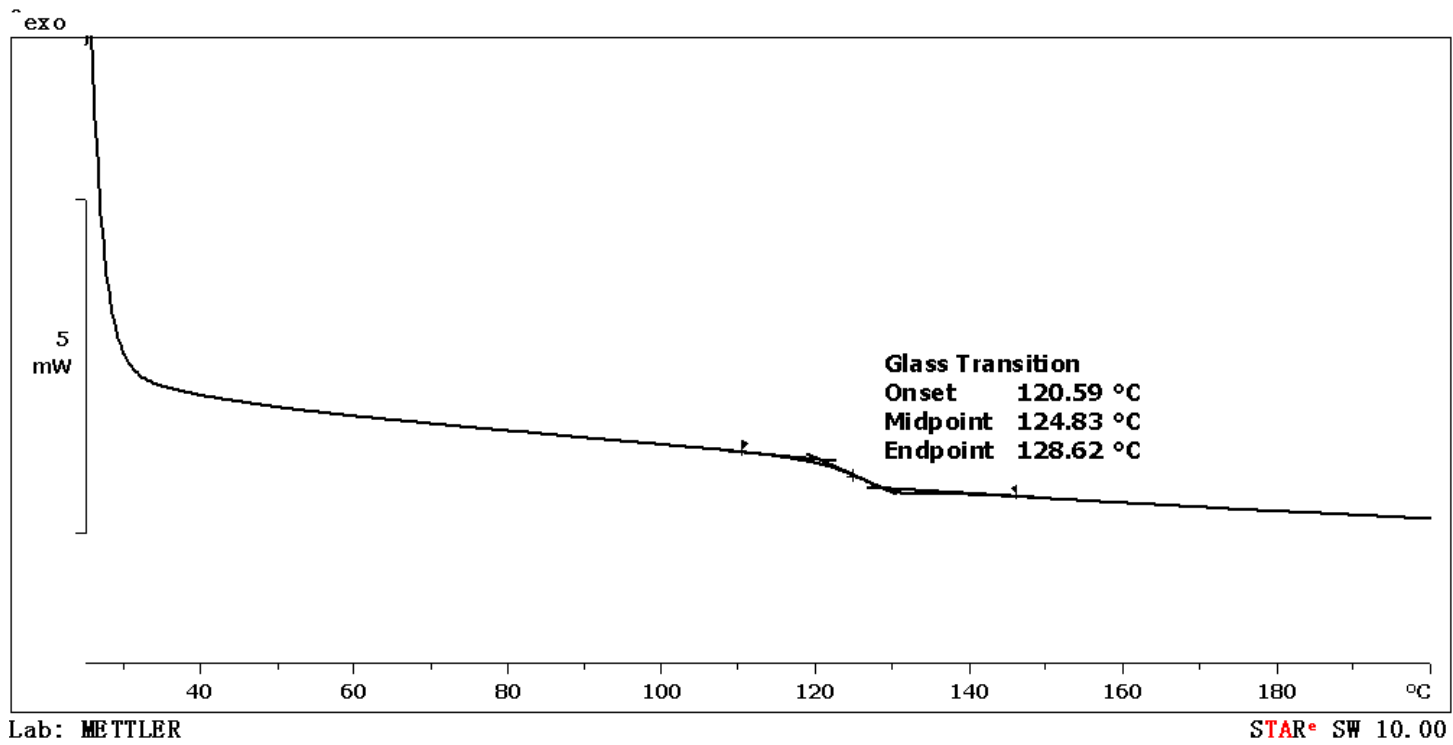

Figure S33. DSC curve of TES-St copolymer containing 10 mol\% TES units (Table 2, run 2) 


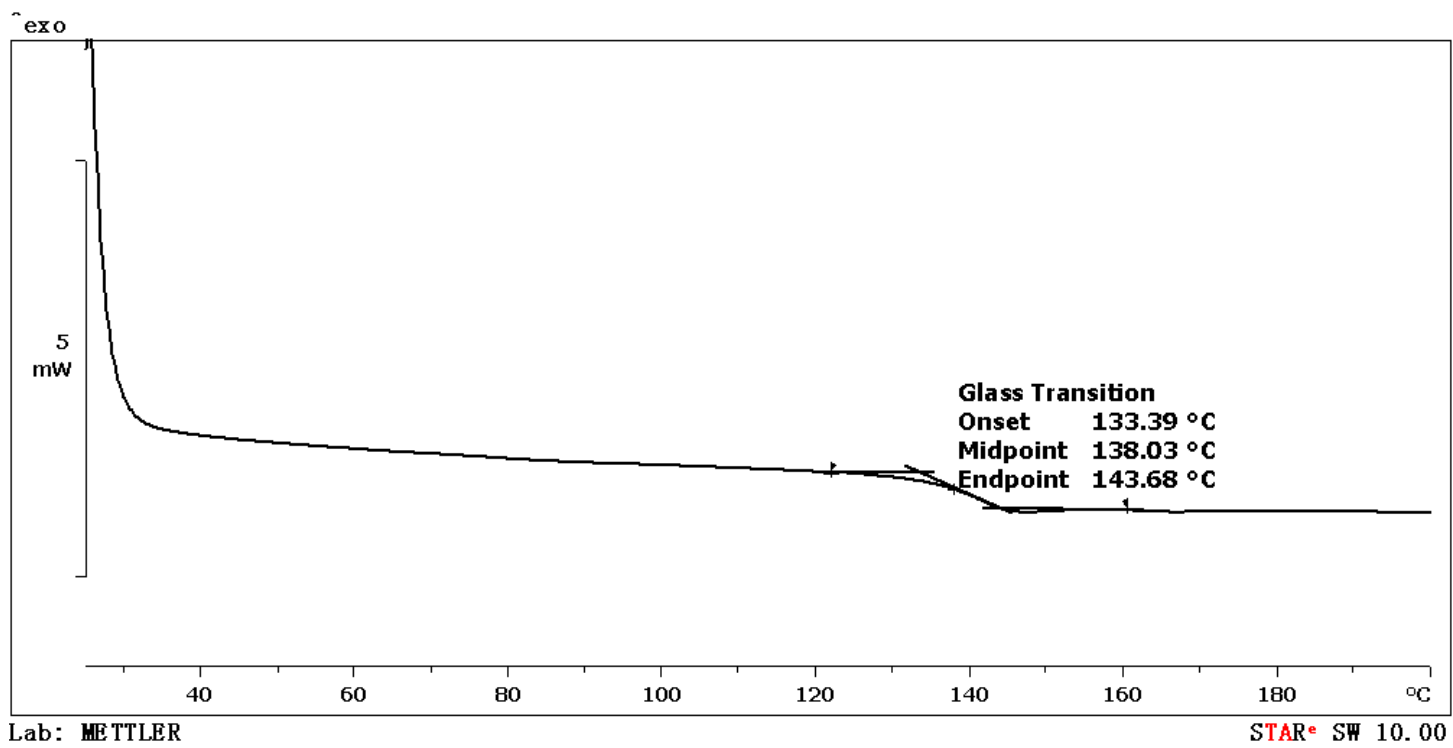

Figure S34. DSC curve of TES-St copolymer containing 50 mol\% TES units (Table 2 , run 4)

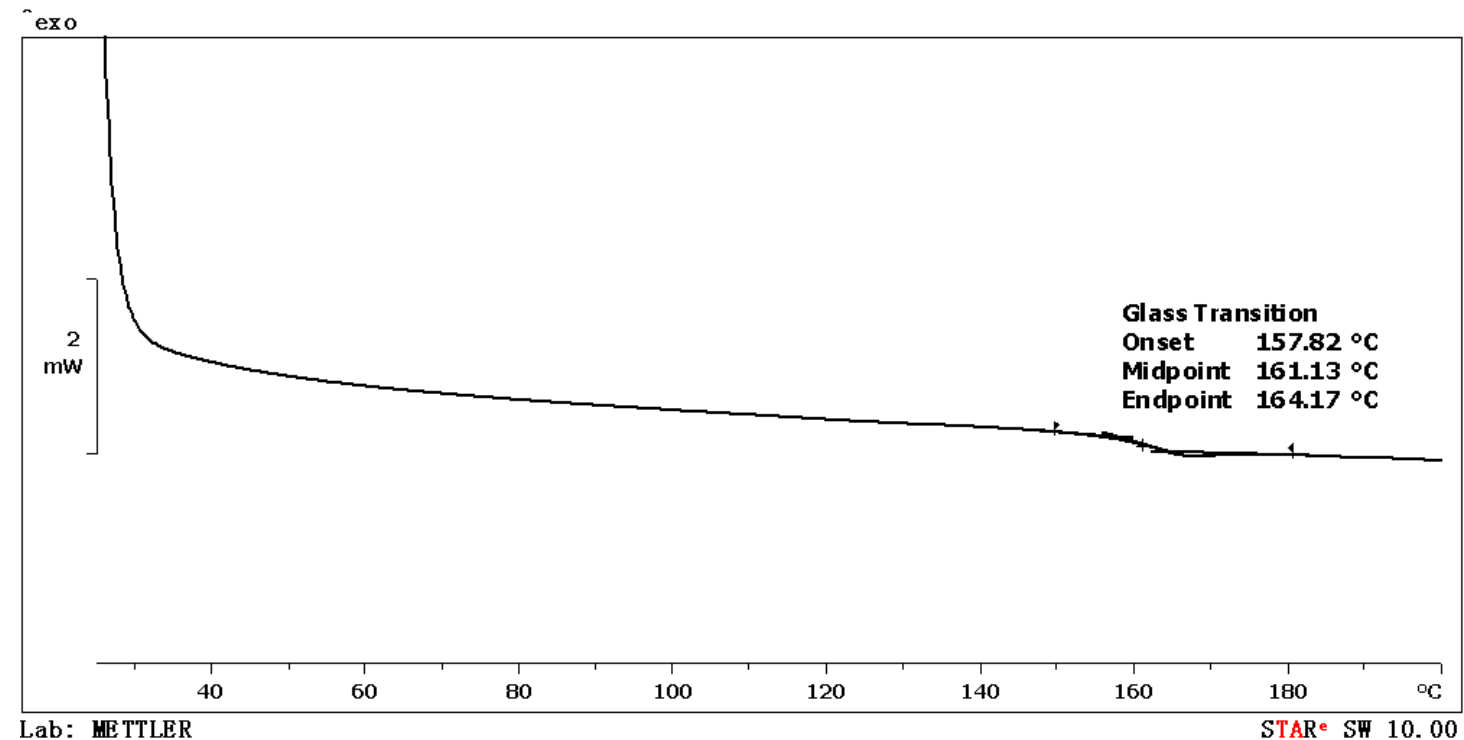

Figure S35. DSC curve of TES-St copolymer containing 90 mol\% TES units (Table 2 , run 6) 


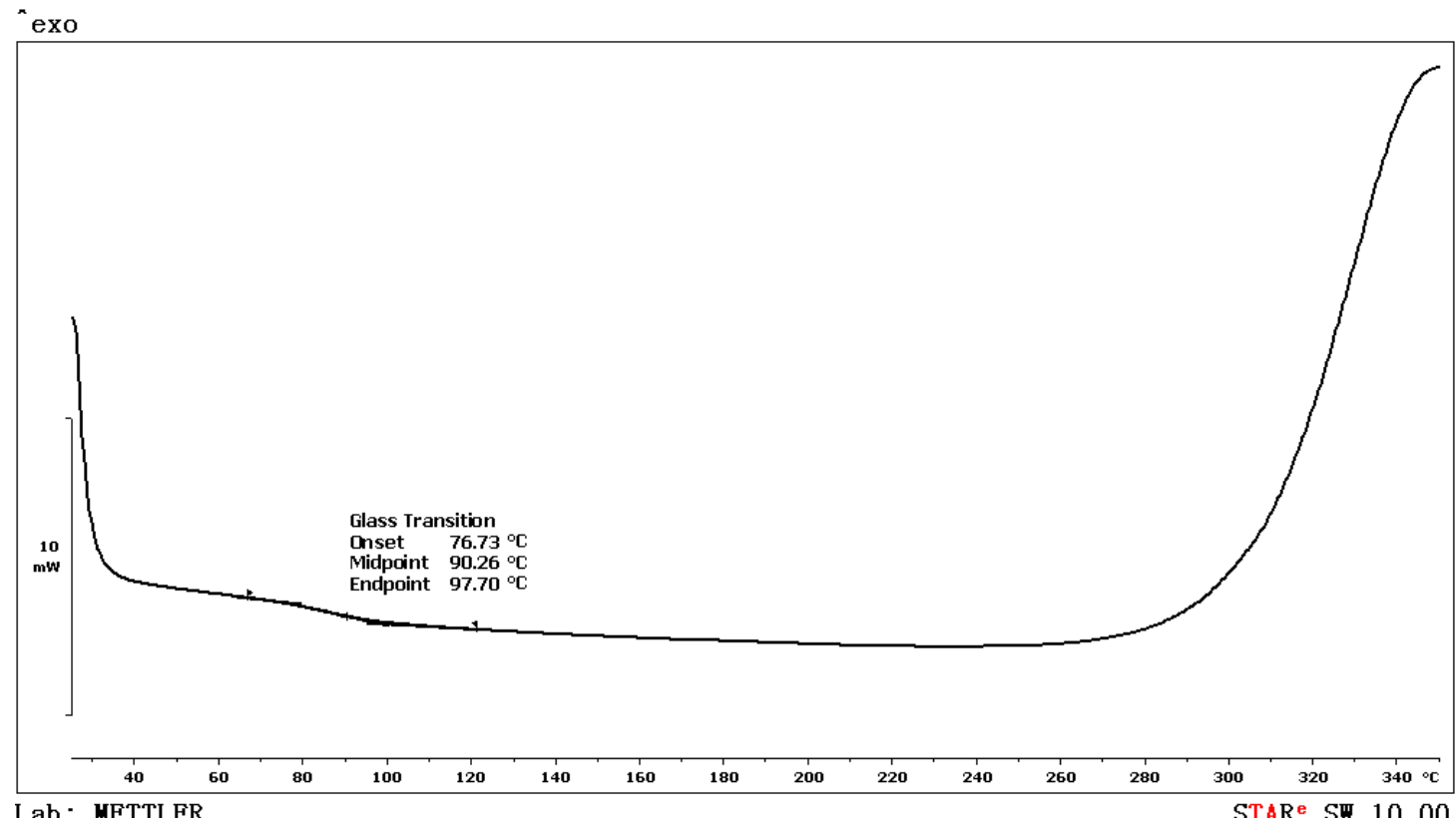

Figure S36. DSC curve of poly(HES) (Table 1, run 4)

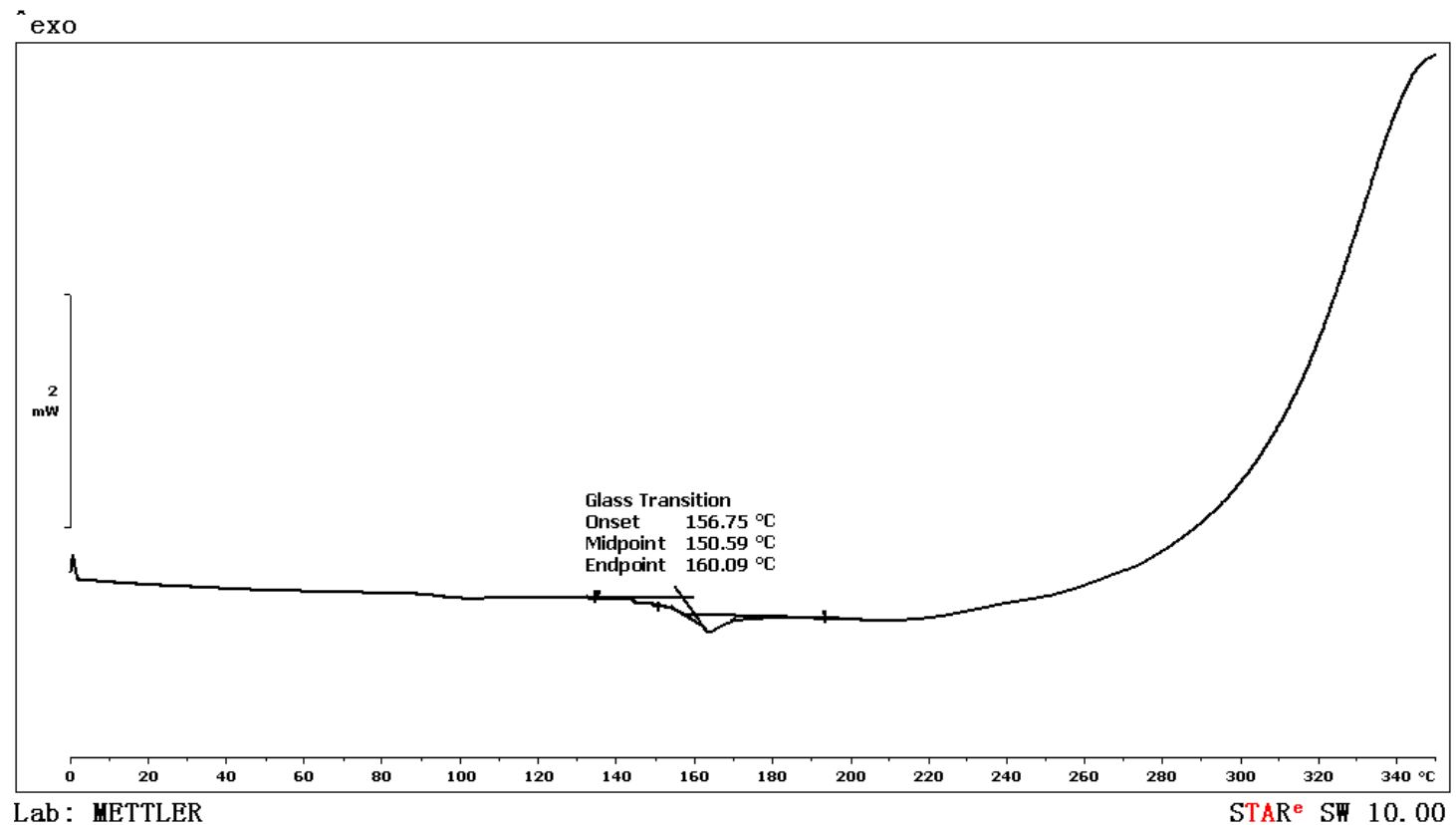

Figure S37. DSC curve of poly(PES) (Table 1, run 8) 


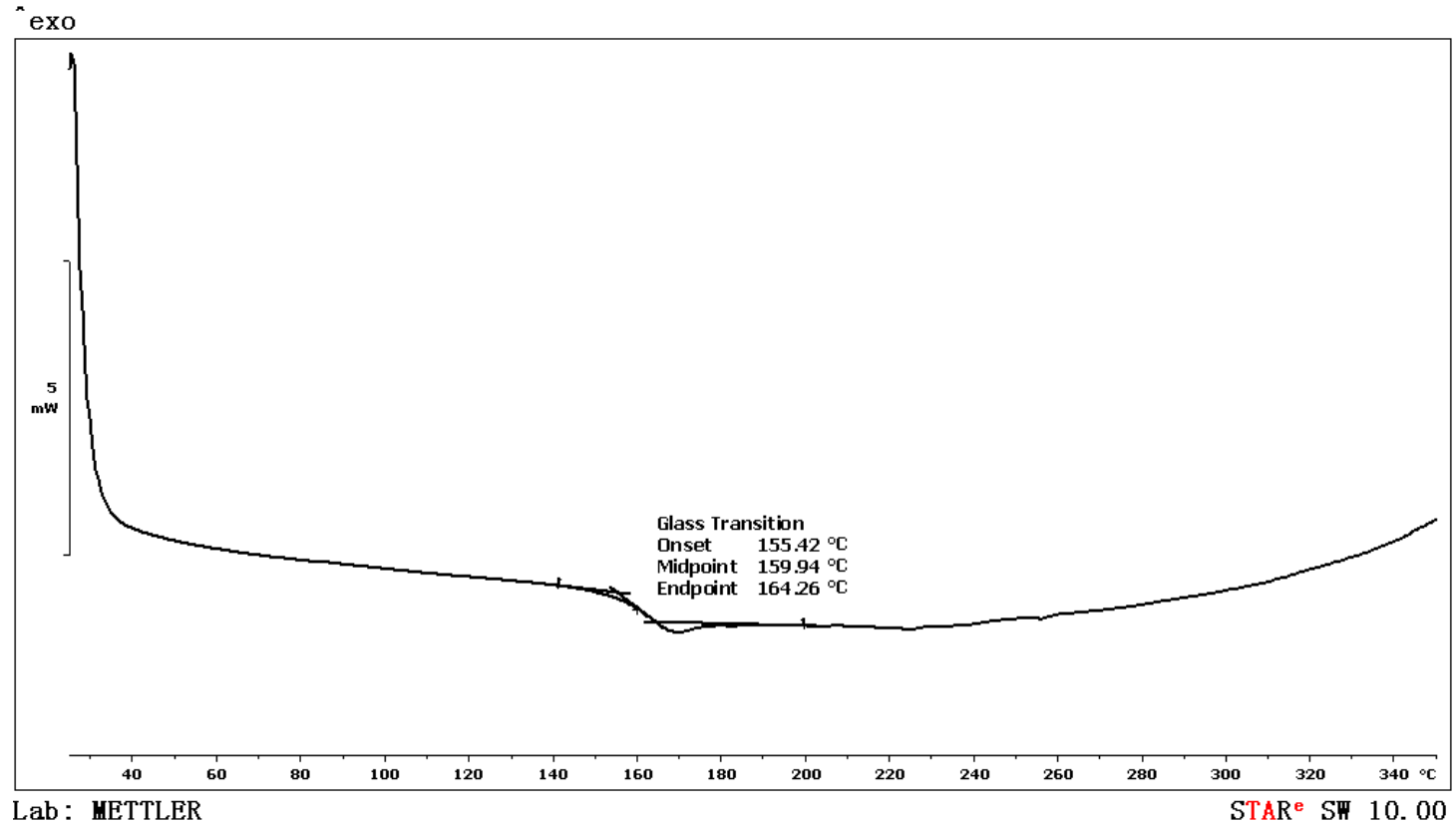

Figure S38. DSC curve of poly(TES) (Table 1, run 15)

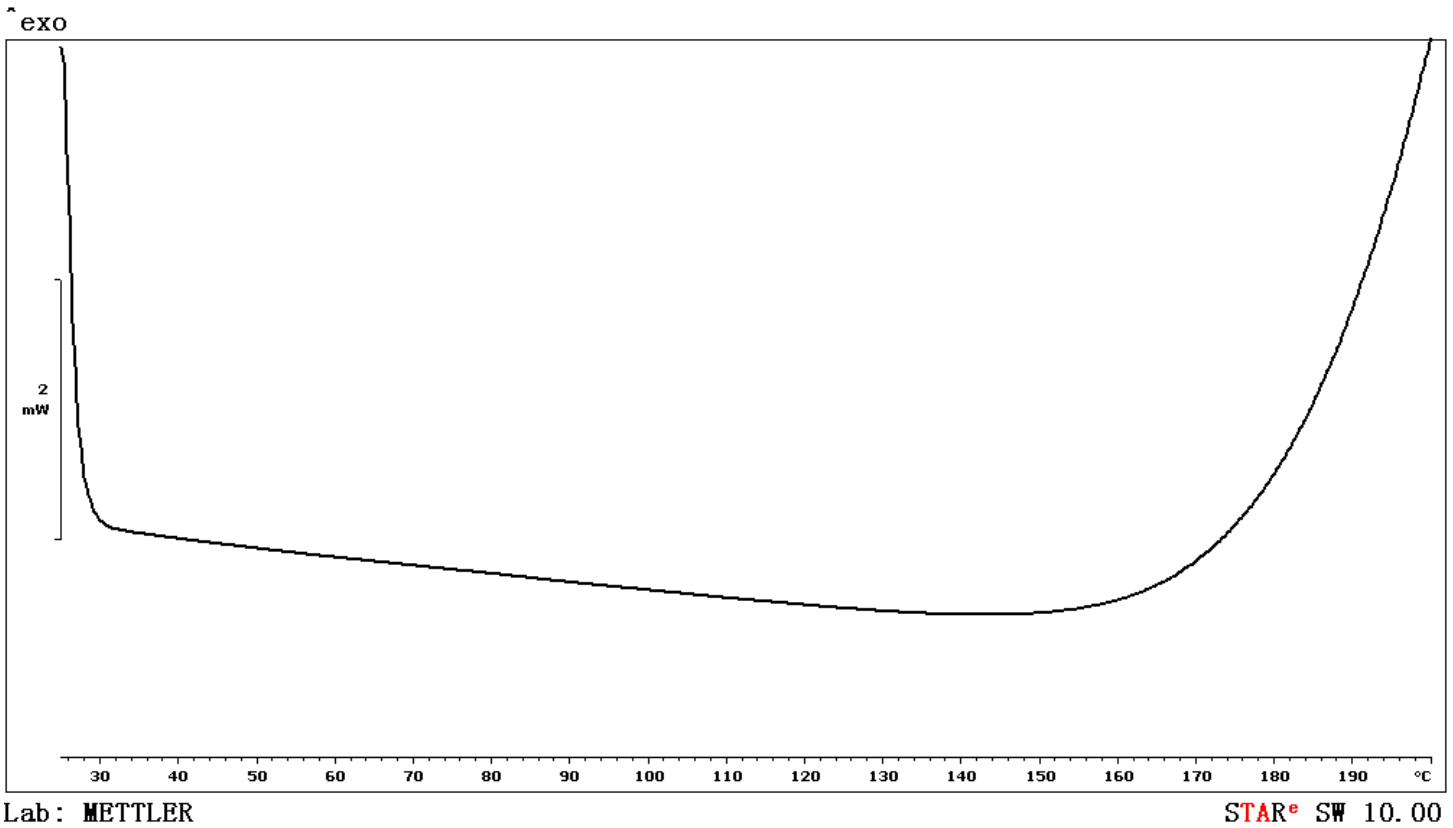

Figure S39. DSC curve of poly(ES) 


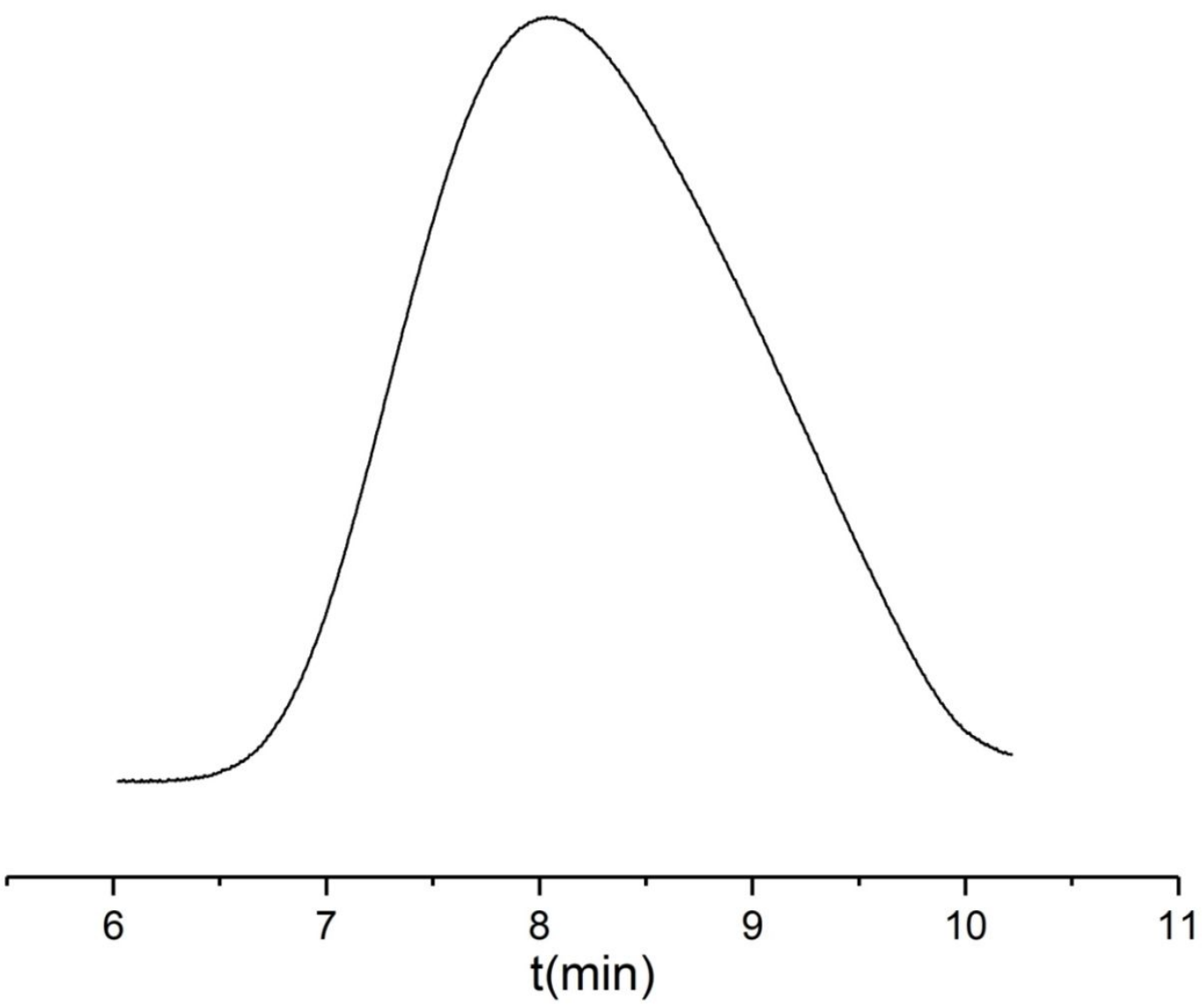

Figure S40. GPC trace of poly(HES) (Table 1, Run 1)

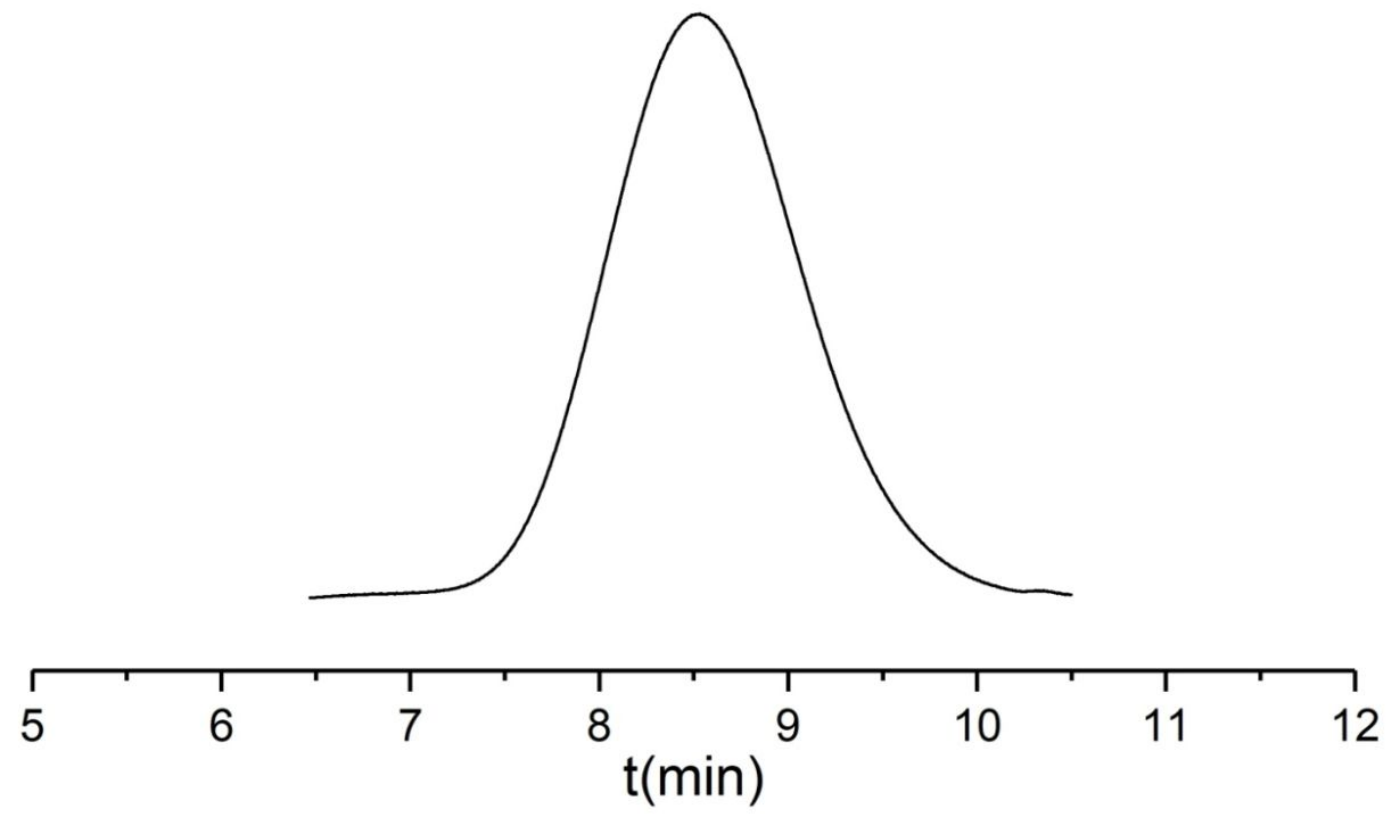

Figure S41. GPC trace of poly(HES) (Table 1, Run 2) 

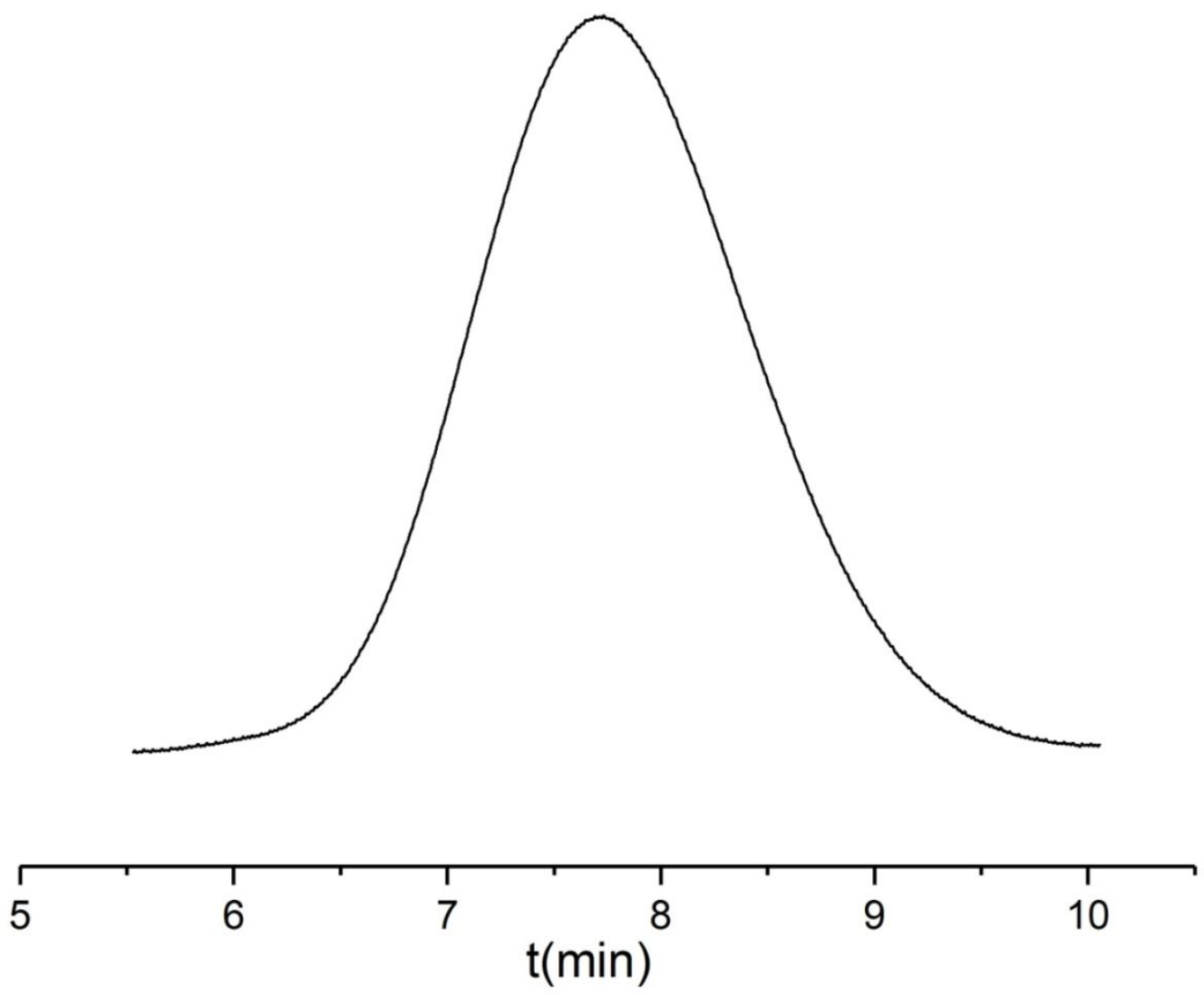

Figure S42. GPC trace of poly(HES) (Table 1, Run 3)



Figure S43. GPC trace of poly(HES) (Table 1, Run 4) 


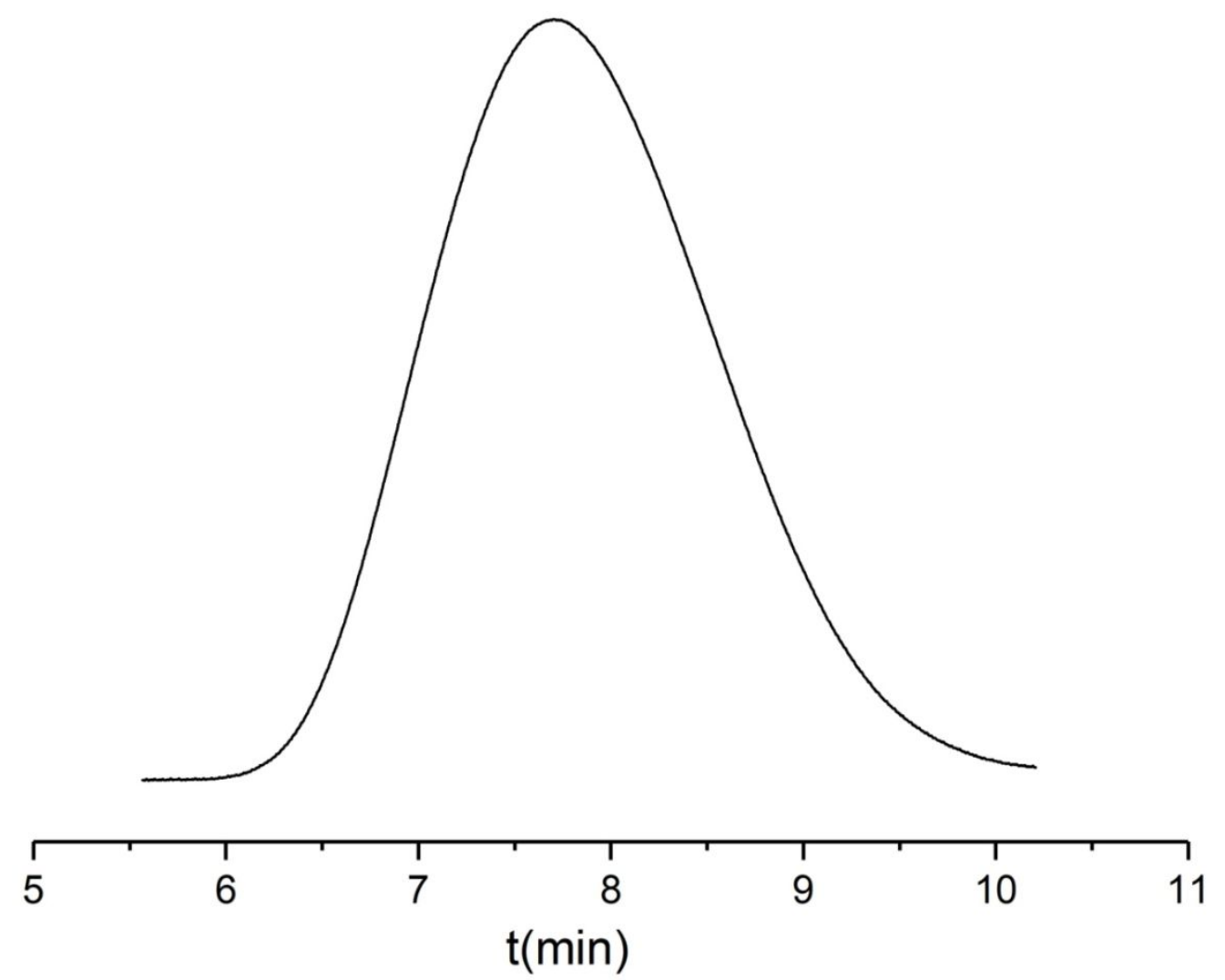

Figure S44. GPC trace of poly(PES) (Table 1, Run 5)

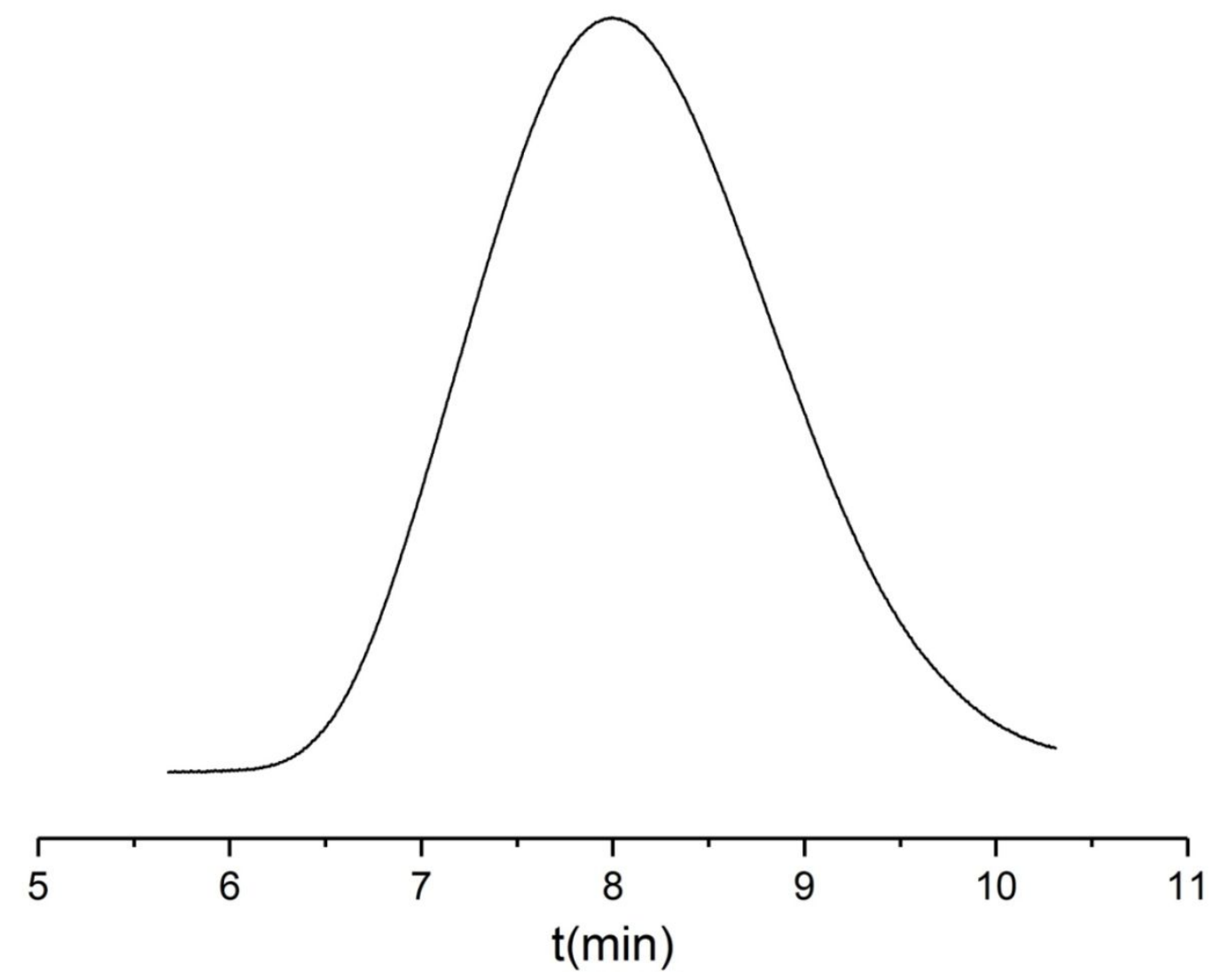

Figure S45. GPC trace of poly(PES) (Table 1, Run 6) 


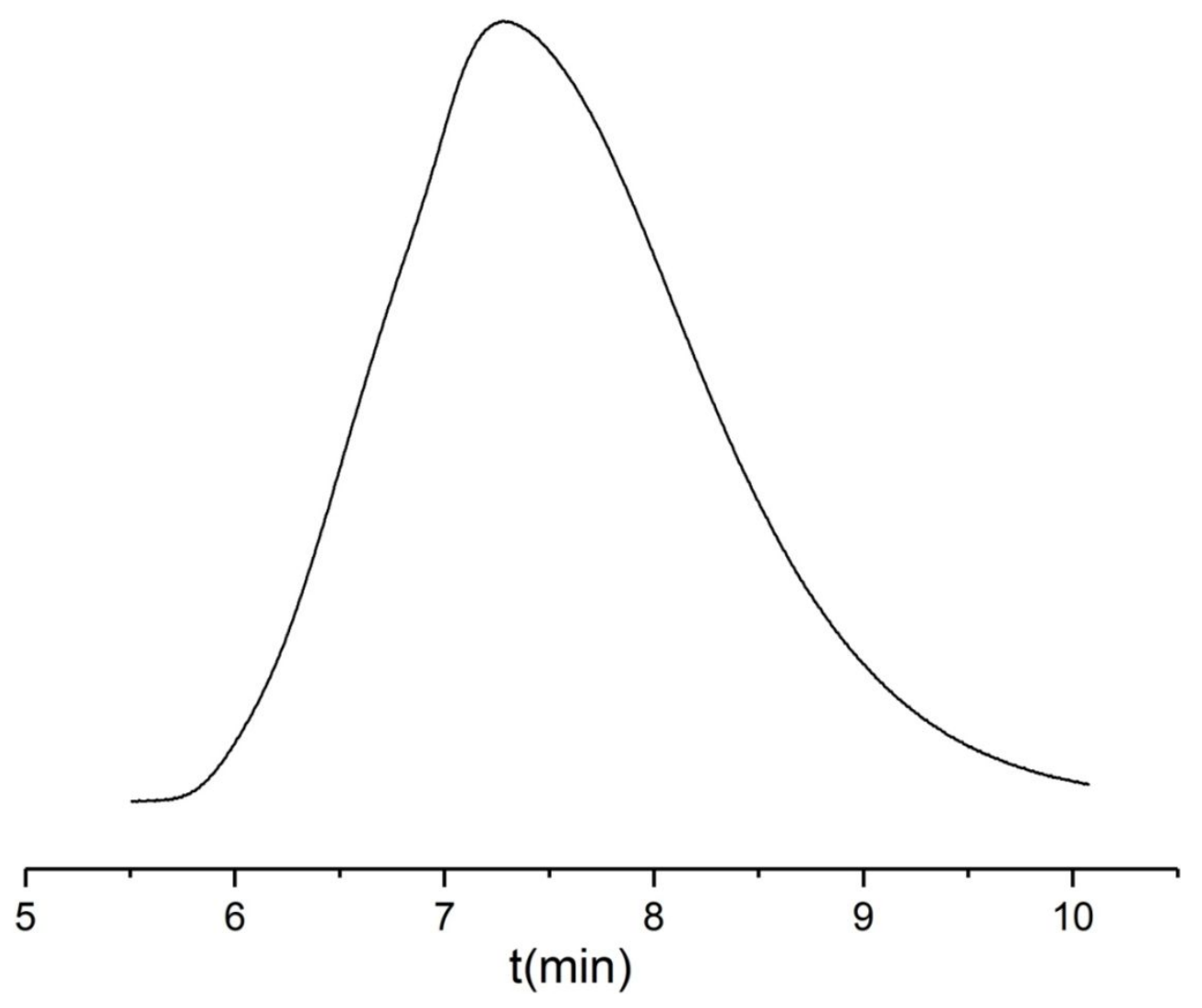

Figure S46. GPC trace of poly(PES) (Table 1, Run 7)

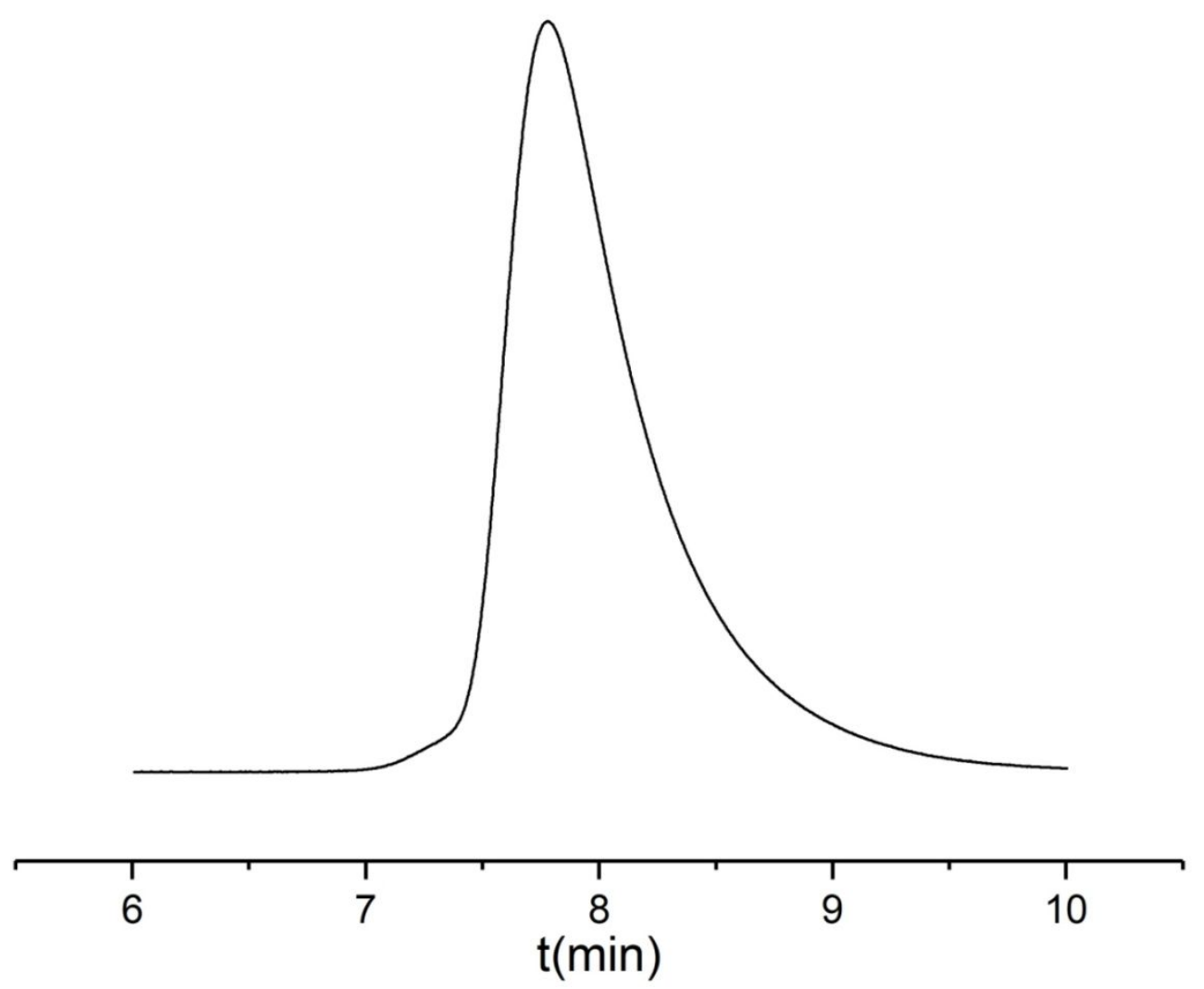

Figure S47. GPC trace of poly(PES) (Table 1, Run 8) 


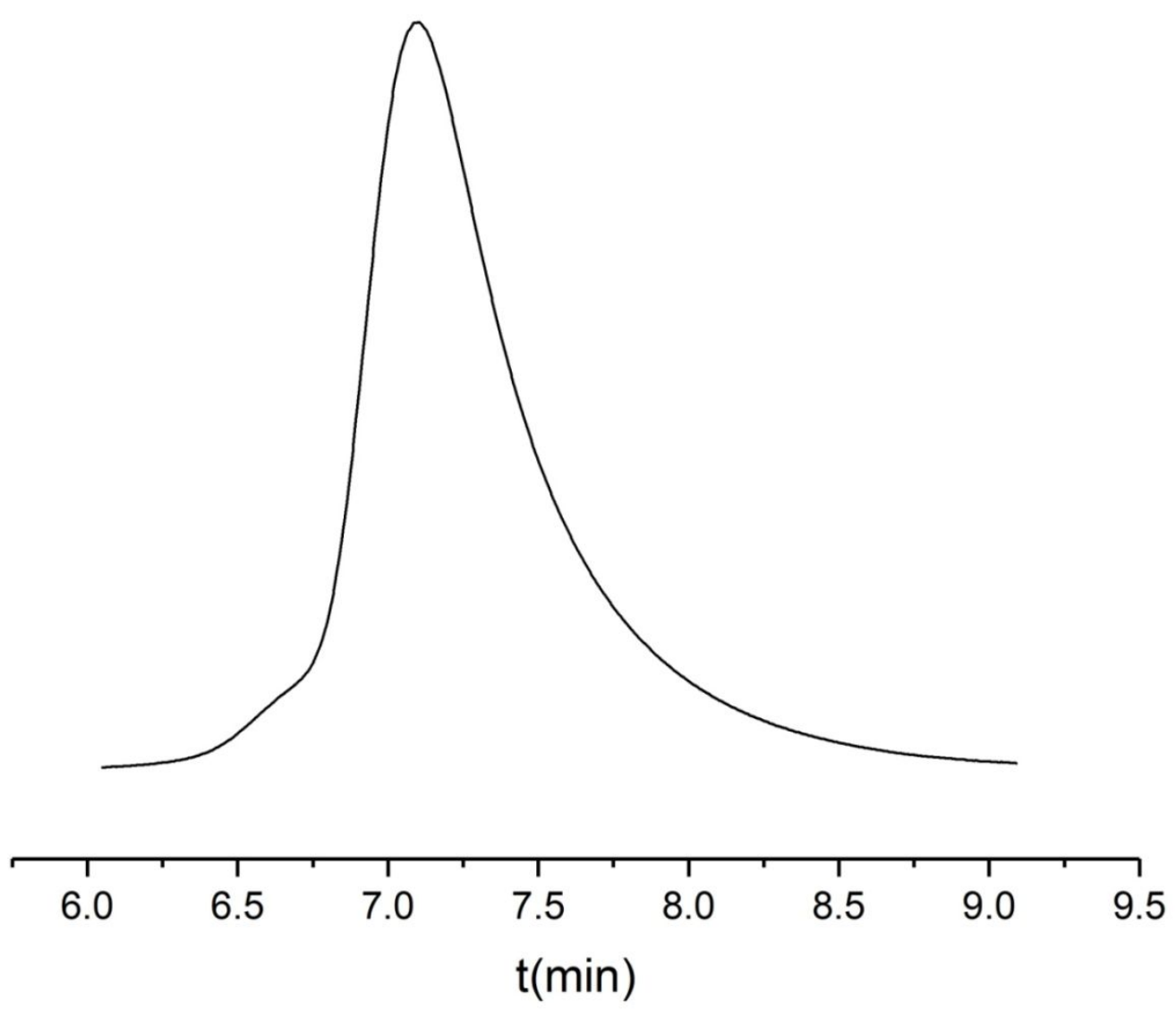

Figure S48. GPC trace of poly(PES) (Table 1, Run 9)

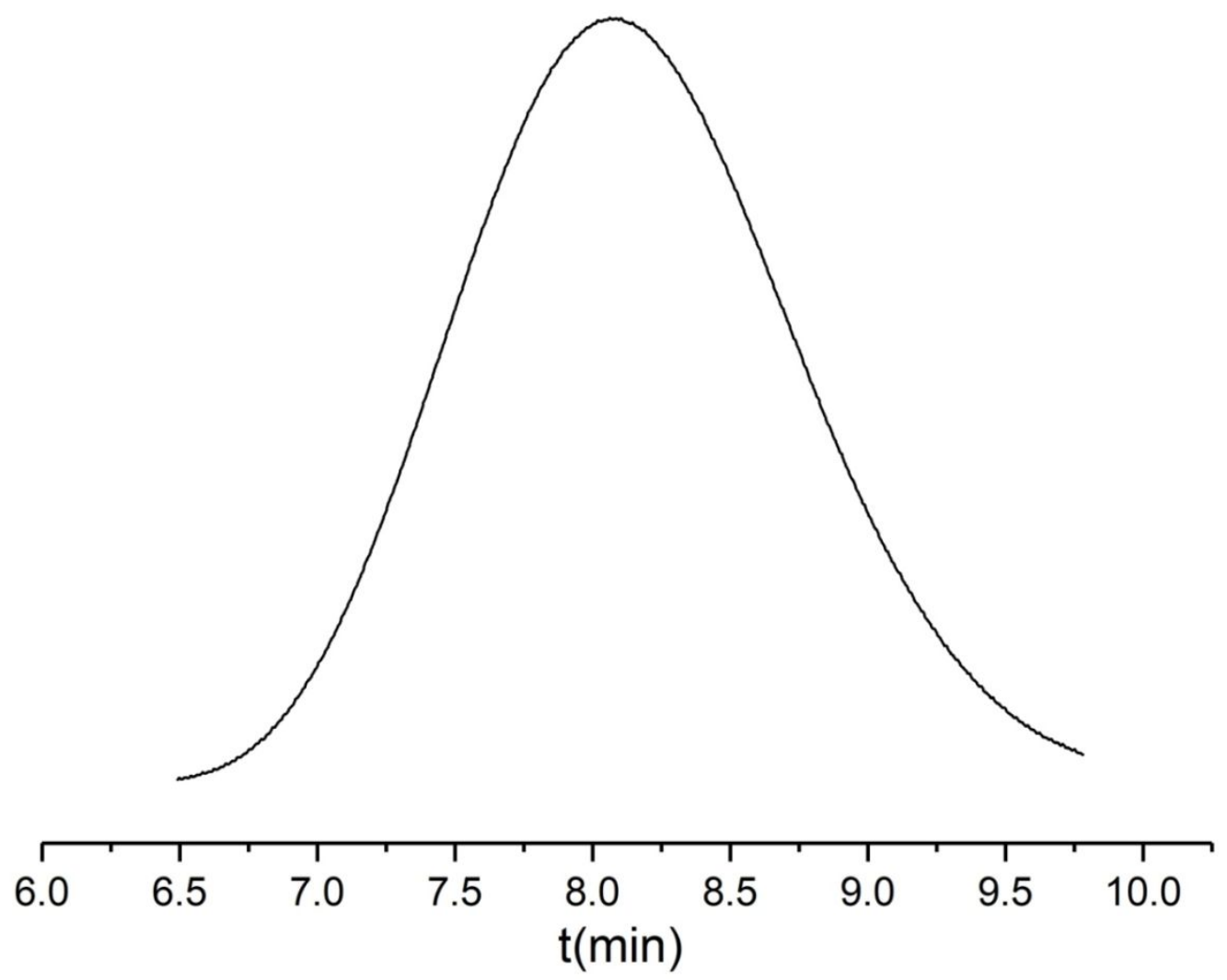

Figure S49. GPC trace of poly(TES) (Table 1, Run 10) 


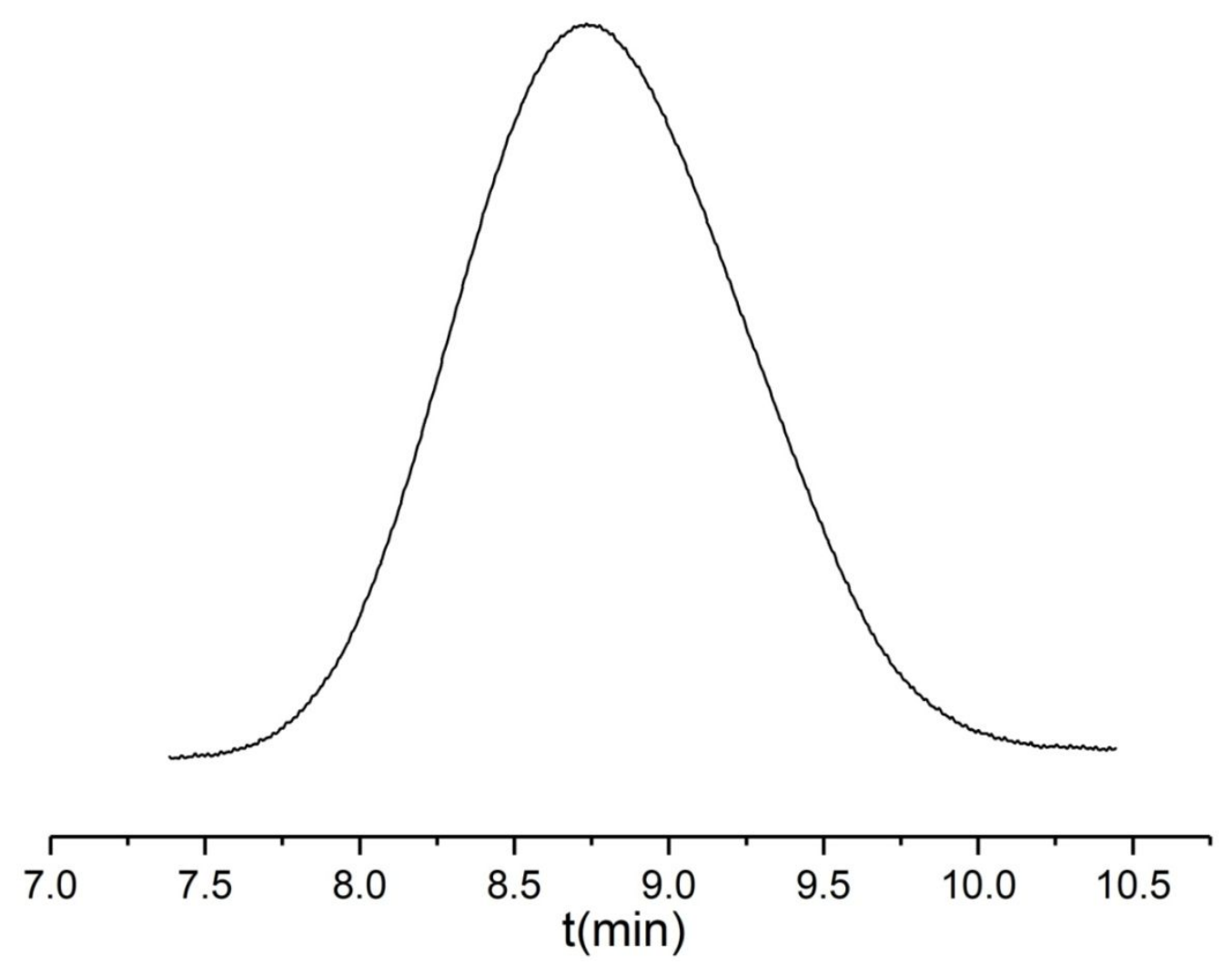

Figure S50. GPC trace of poly(TES) (Table 1, Run 12)

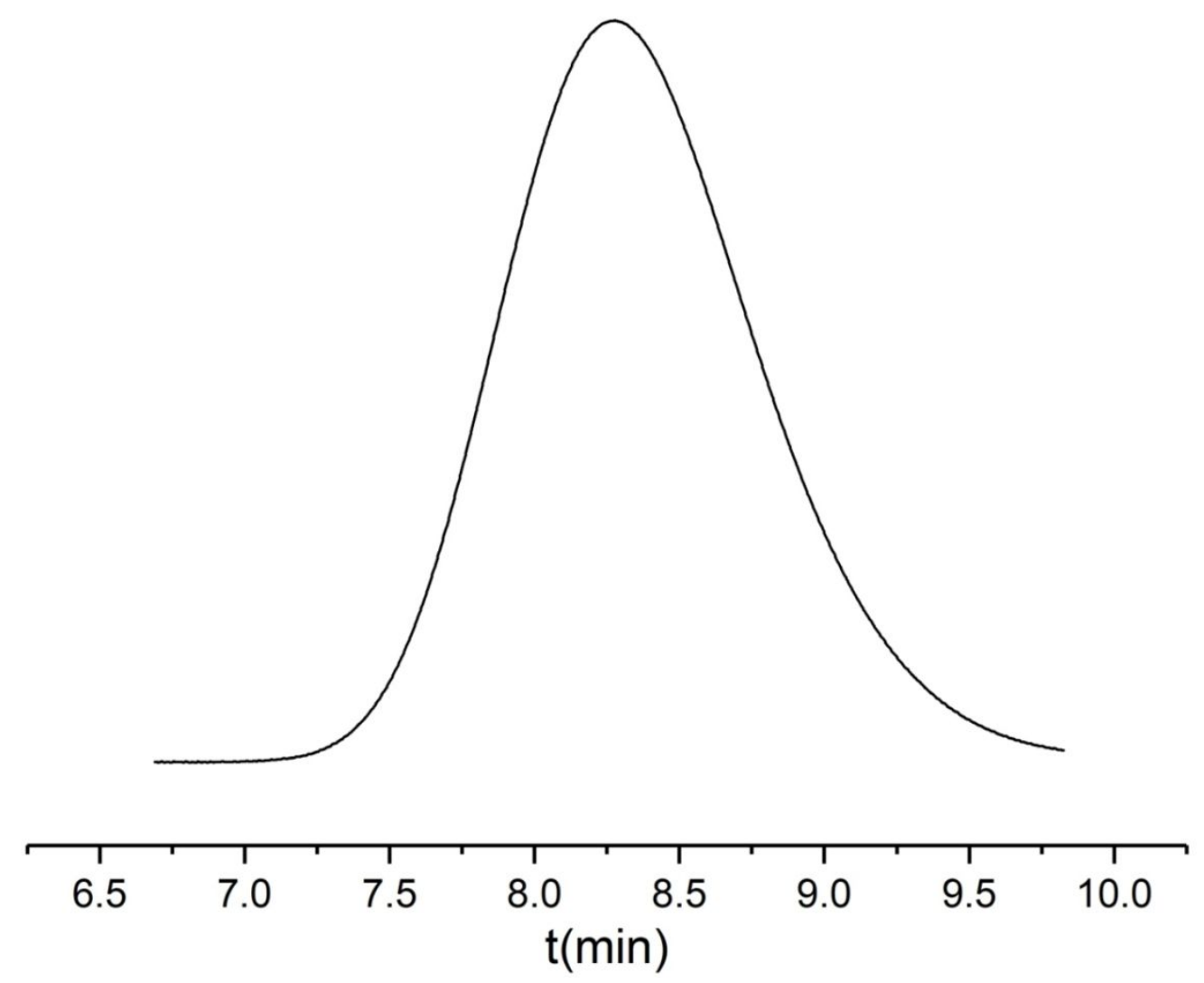

Figure S51. GPC trace of poly(TES) (Table 1, Run 13) 


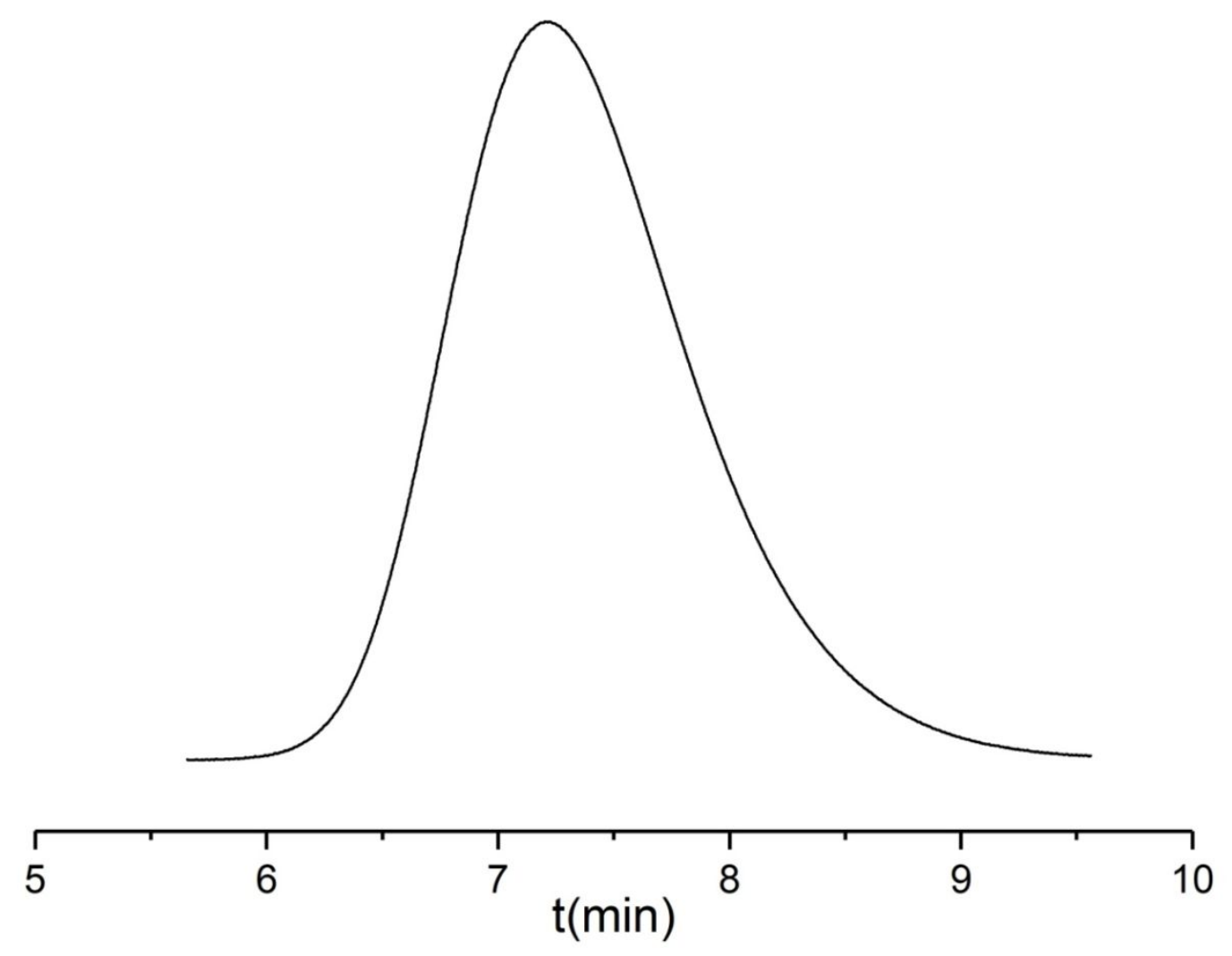

Figure S52. GPC trace of poly(TES) (Table 1, Run 14)

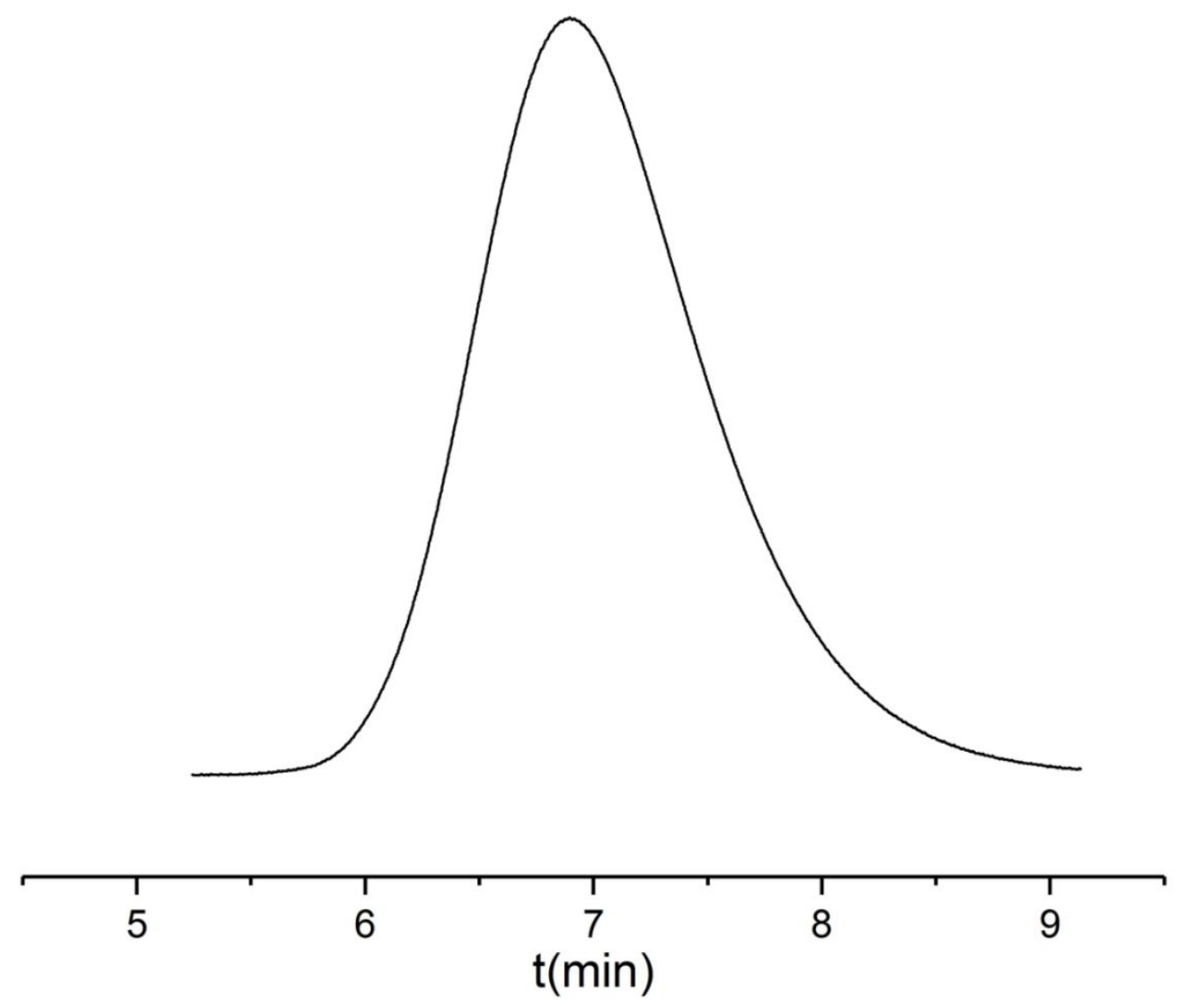

Figure S53. GPC trace of poly(TES) (Table 1, Run 15) 

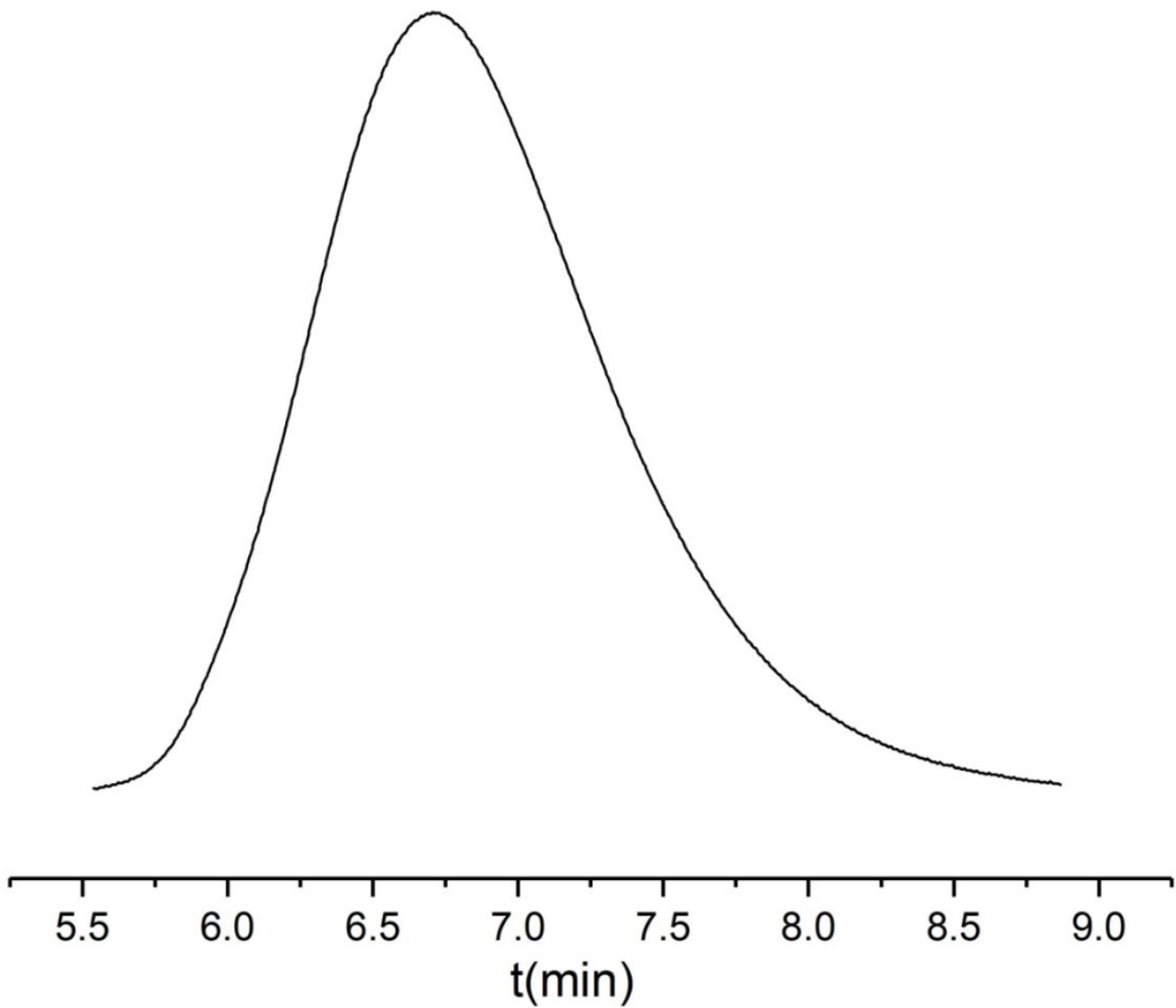

Figure S54. GPC trace of poly(TES) (Table 1, Run 16)



Figure S55. WAXS profiles of alkyne-substituted polystyrenes. 